\title{
الابداعُ اللغويٌُ ومكوناته عند الدكتور تمام حسان
}

\author{
أ.م.د. قصي سمير عبيس العزاوي

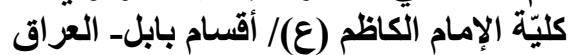 \\ الايميل: Sq5y425@gmail.com
}

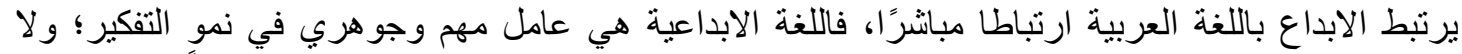

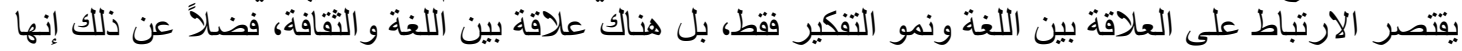

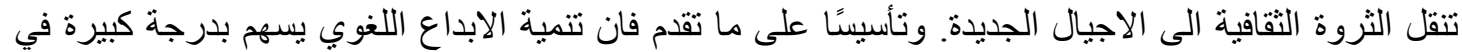

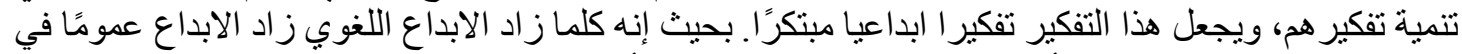

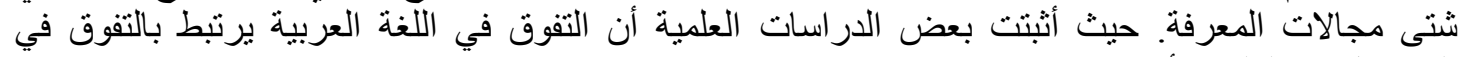

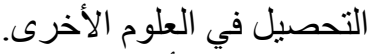

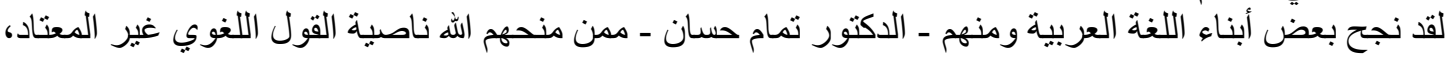

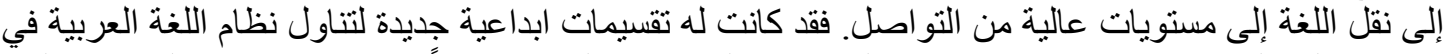

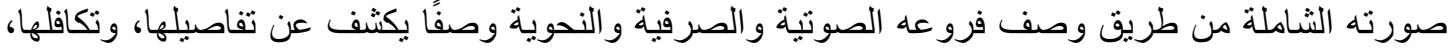

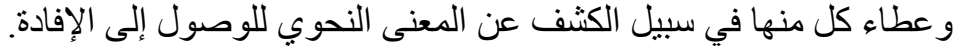

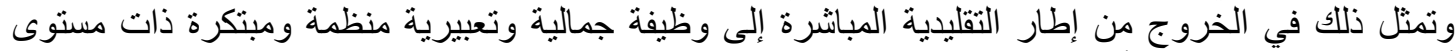

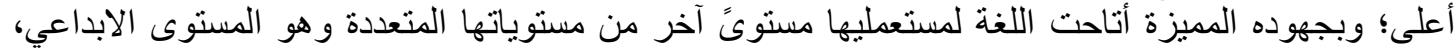

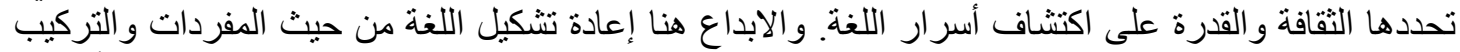

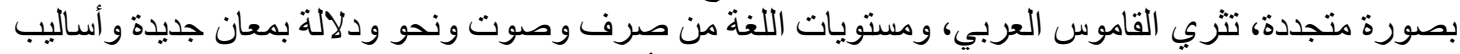

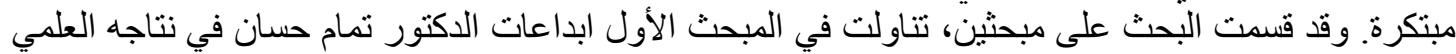

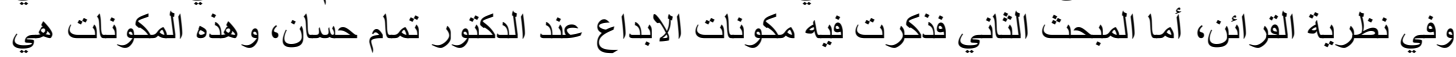

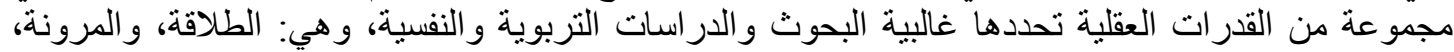

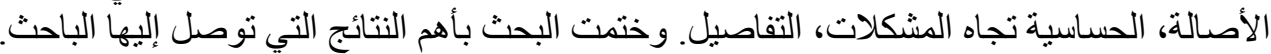




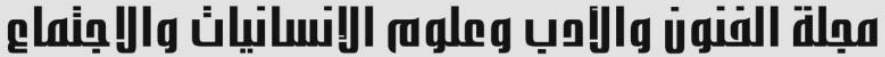

Journal of Arts, Literature, Humanities and Social Sciences www.jalhss.com

\section{Linguistic Creativity and Components for Dr. Tammam Hassan}

\author{
Dr. Qusay Sameer Obyies ALazawi \\ College AL Imam AL Kadhim Human Science/Babylon sections- Iraq \\ Email: Sqsy425@gmail.com
}

\begin{abstract}
Creativity is directly related to the Arabic language. Creative language is an important and fundamental factor in the growth of thinking. The link is not limited to the relationship between language and the growth of thinking only.

Some of the sons of the Arabic language, including Dr. Tammam Hassan, have succeeded in transferring the language to high levels of communication. It had new creative divisions to address the Arabic language system in its comprehensive form by describing its phonological, grammatical and grammatical branches, a description that reveals its details, its interdependence, and a bid for each of them in order to reveal the grammatical meaning to reach the benefit.

This was represented in leaving the framework of direct traditionalism to a function of aesthetic, expressive, organized and innovative at a higher level; and with its distinguished efforts, the language allowed its users to another level of its multiple levels, which is the creative level, determined by culture and the ability to discover the secrets of the language. The research was divided into two topics, which dealt in the first topic with the creations of Dr. Tammam Hassan in his scientific output and in the theory of clues. As for the second topic, I mentioned the components of creativity for Dr. Tammam Hassan, and these components are a set of mental capabilities determined by the majority of educational and psychological studies and studies, They are: fluency, flexibility, originality, sensitivity to problems, detail. And the research concluded with the most important results reached by the researcher.
\end{abstract}

Keywords: figural fluency, Sensitivity to Problems, Dr. Tammam Hassan. 


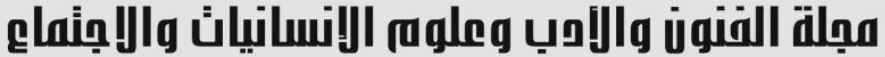

Journal of Arts, Literature, Humanities and Social Sciences

www.jalhss.com

Volume (50) March 2020
العدد (50) مارس 2020 (20)

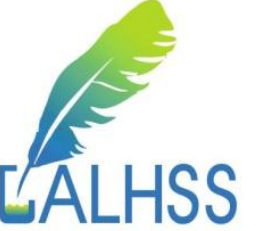

المقدمة

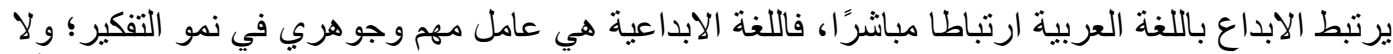

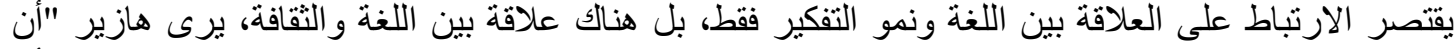

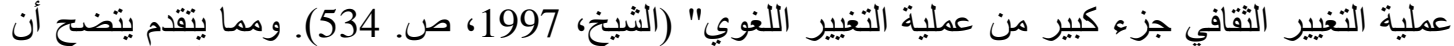

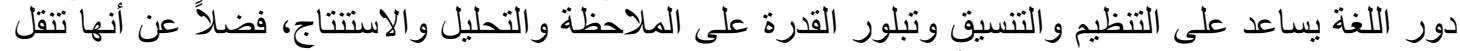

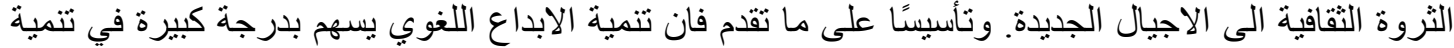

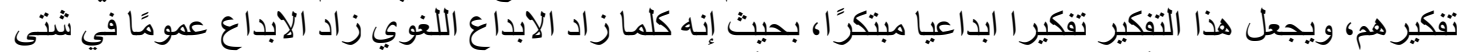

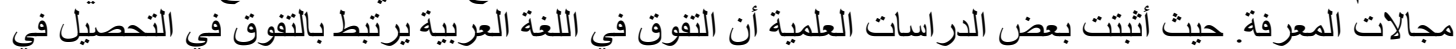

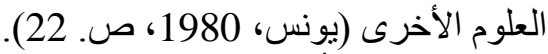

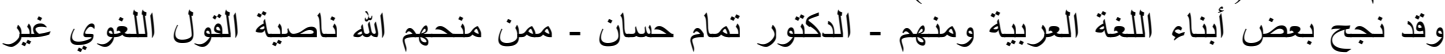

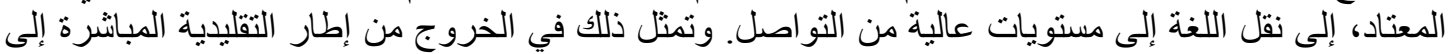

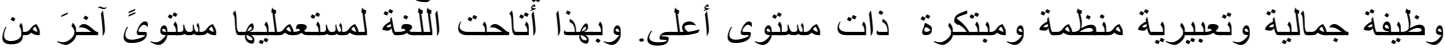

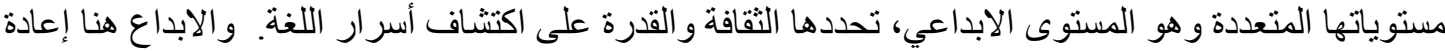

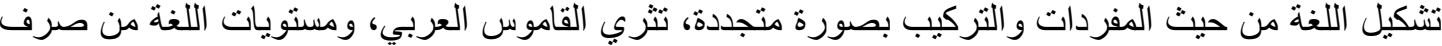

وصوت ونحو ودلالة بمعان جديدة و أساليب مبتكرة المئه

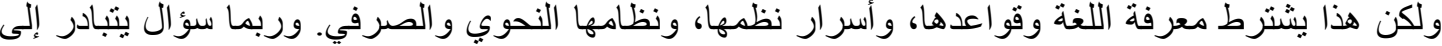

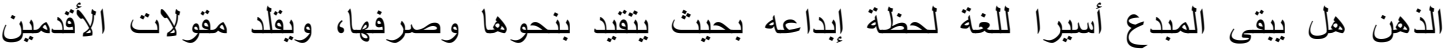

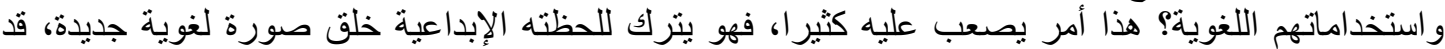

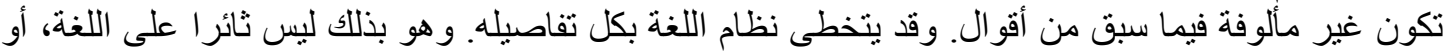

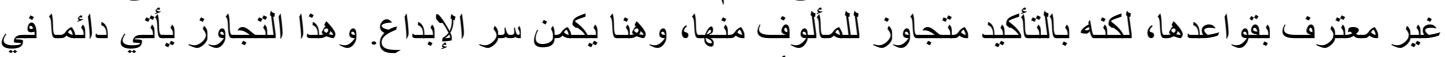

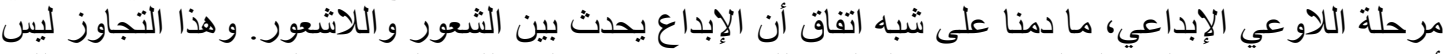

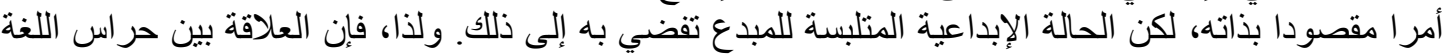

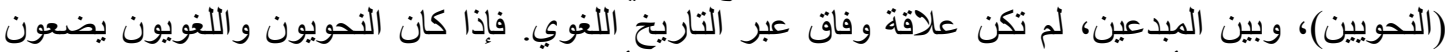

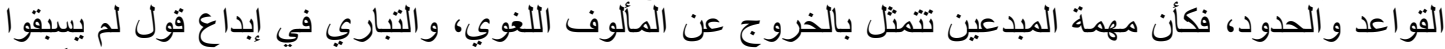

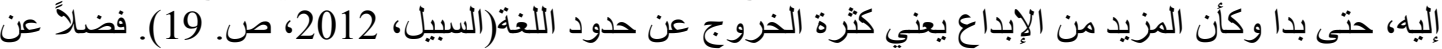

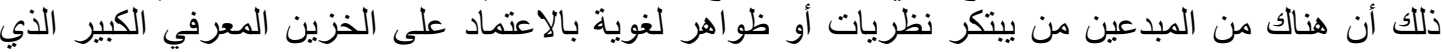

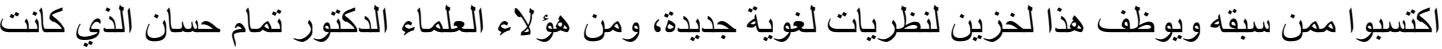

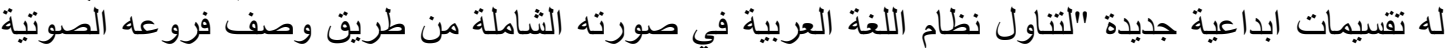

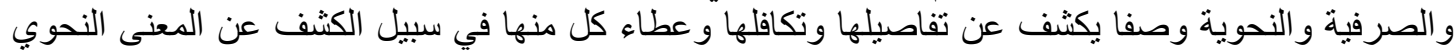

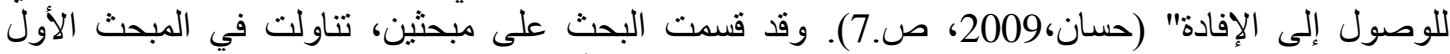

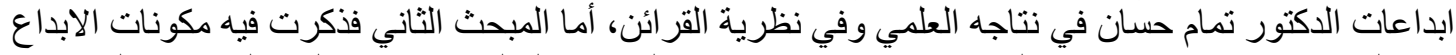

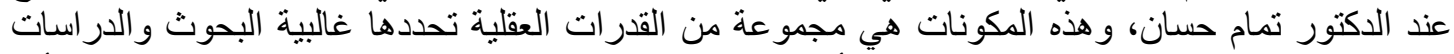
التربوية و النفسية، و هي: الطلاقة، و المرونة، الأصالة، الحساسية تجاه المشكلات، التفاصيل. وختمت البحت البحث بأهم النتائج التي توصل إلنها الباحث.

\section{المبحث الأول \\ ابداعات الدكتور تمام حسان في نتاجه العلمي وفي نظرية القرائن}

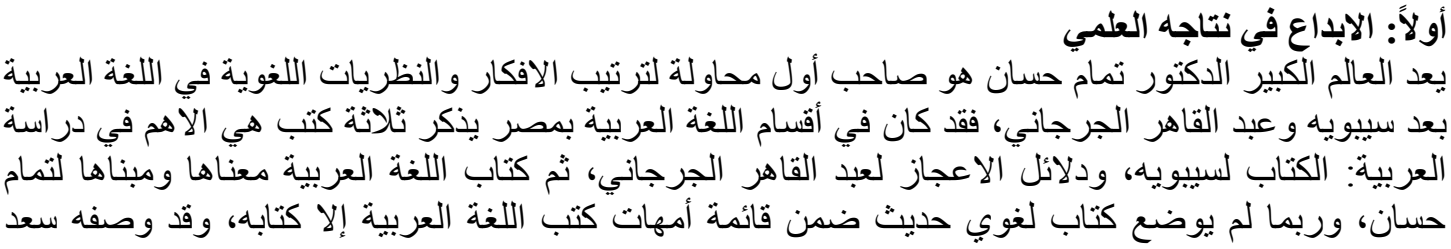




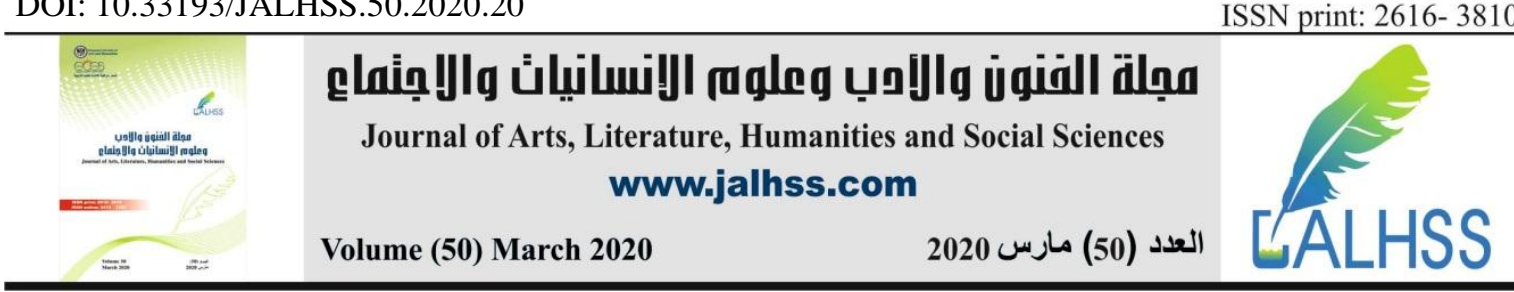

مصلوح بـ(الكتاب الجديد) بعد كتاب سيبويه الذي سمي بالكتاب كما لو كان أصل كتب العربية(حسان، 2012،

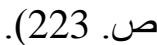

وليس من نافلة القول إن قلت إن: لقد استطاع الدكتور تمام حسان في ضوء أعمأ أعماله العلمية المؤلف منها و المترجم

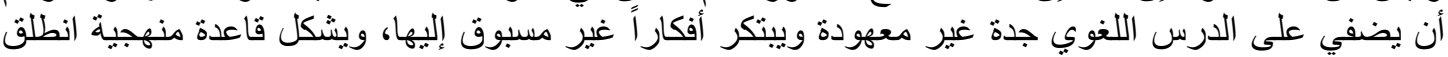

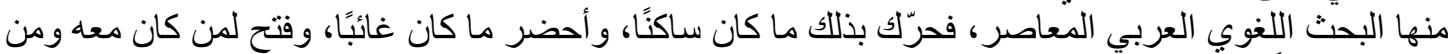

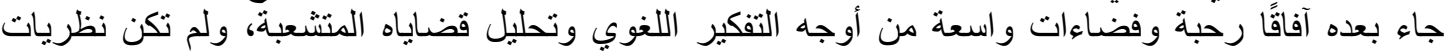

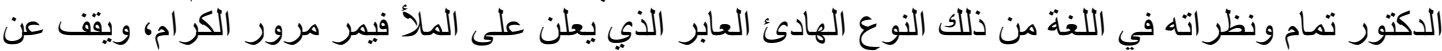

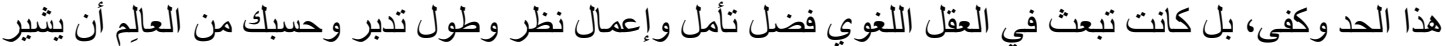

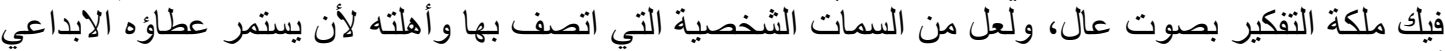

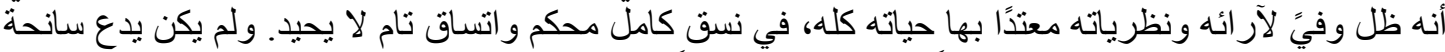

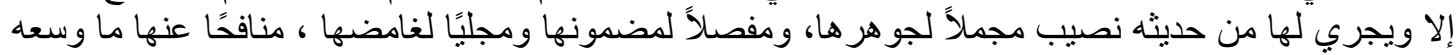

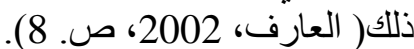

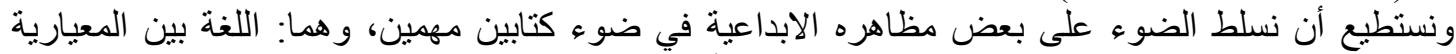

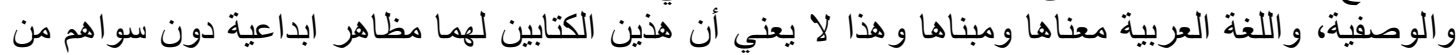

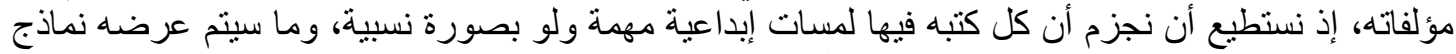

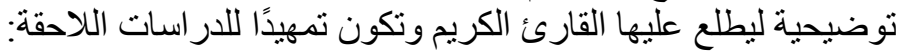

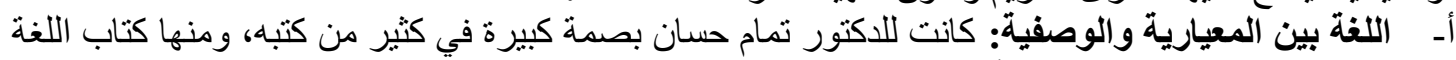
بين المعيارية و الوصفية، ولعل من أهم سماته الابداعية الهية:

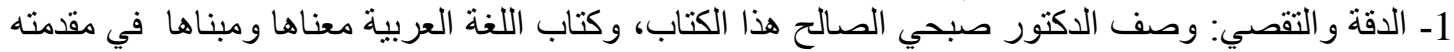

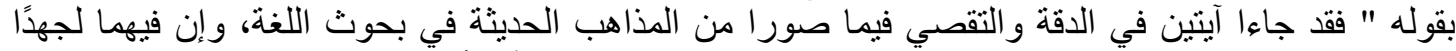

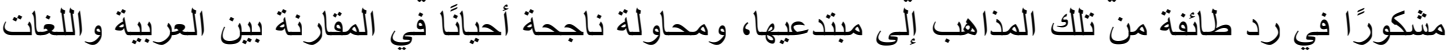

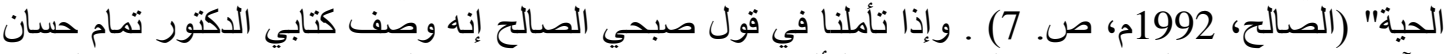

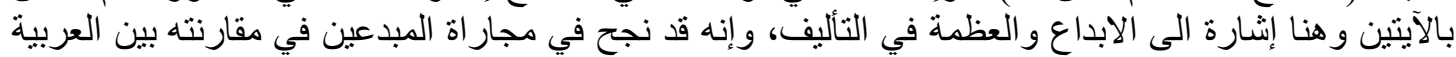

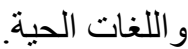

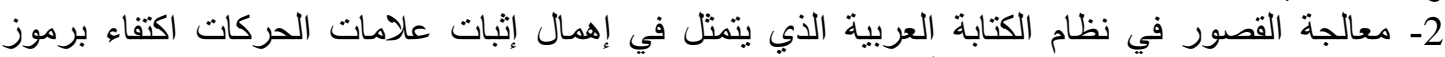

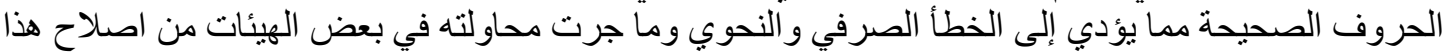

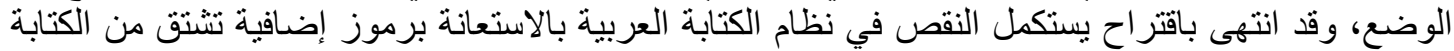

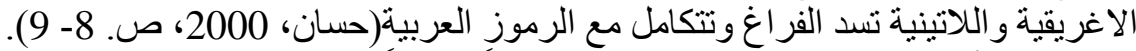

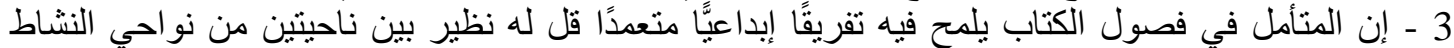

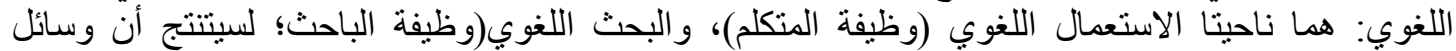

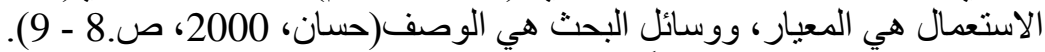

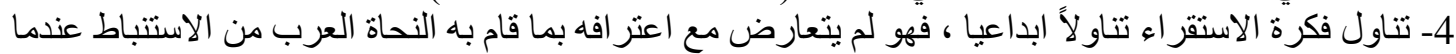

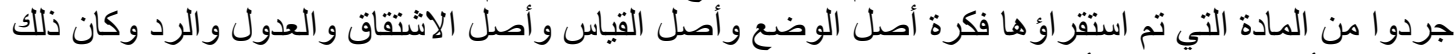

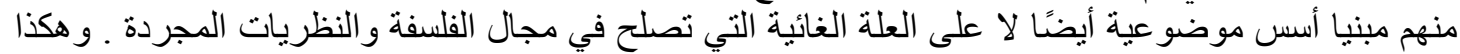

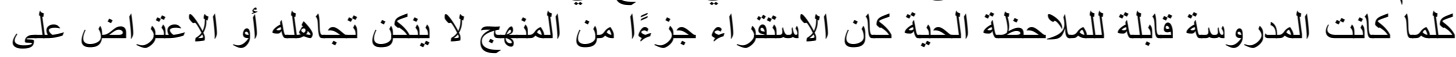

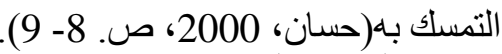

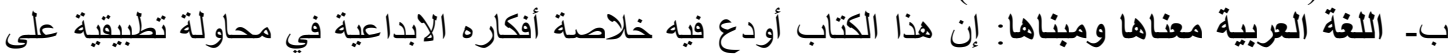

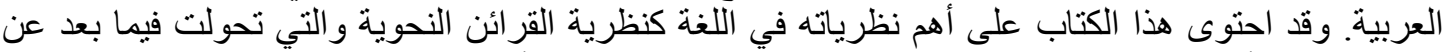

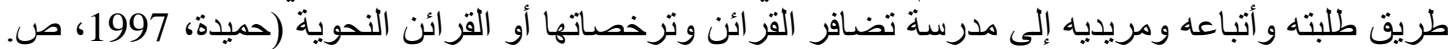

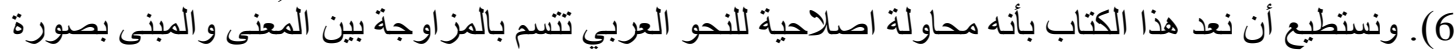

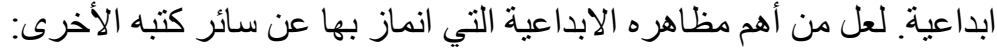

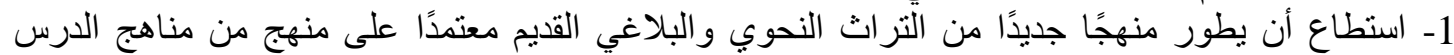

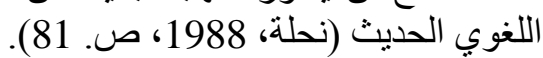




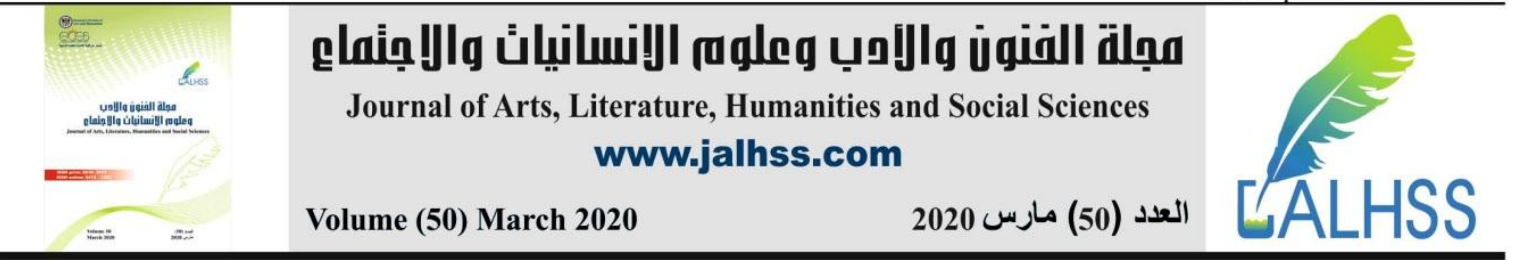

2- تقسيم جديد للكلم يقوم على فروق في المعنى و المبنى، ثم التفريق بين مفهوم الصيغة الصرفية و الميزان

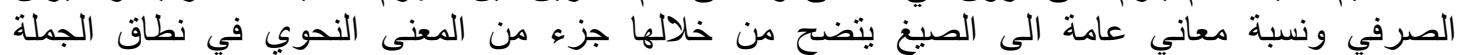

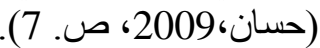

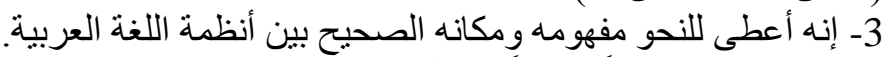
4- إن له أسلوبًا تعليميَّا ابداعيًا مميزًا.

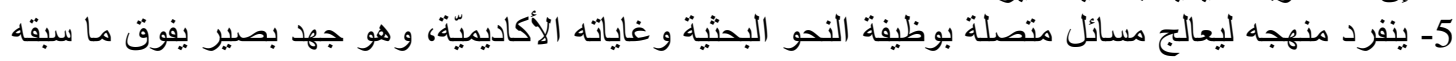

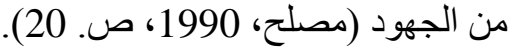
6 - انشاء مبدأ نظري ينبني على نعدد المعنى الوظيفي لحروف المعاني و الأدوات و الضمائر و المعنى المعجمي

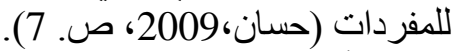
7- إنه أبدع في تجديد حقبقي في مقاربة اللغة العربية، ونسنطيع أن نصنفه نموذجًا جديدًا بإزاء المدرسة

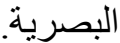
8- أبدع أيما إبداع في در اساته النقدية وفق المنهج الوصفي البنيوي(خليل، 1988، ص. 240).

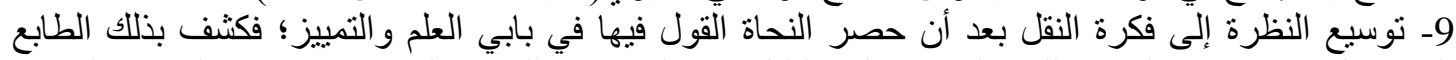

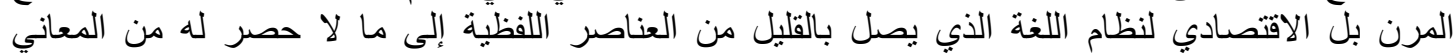
(حسان،2009، ص. 7) 7). ، ولذللك أكد بعض علماء العربية بأنه له السبق في تجديد لبعض قضايا النحو(الثريف،

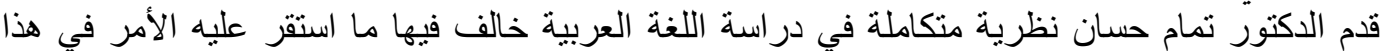

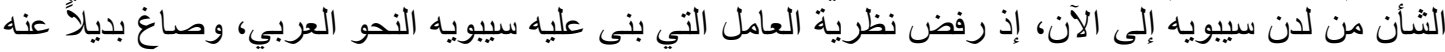

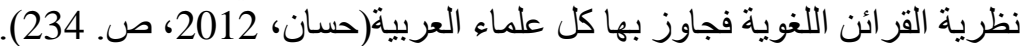

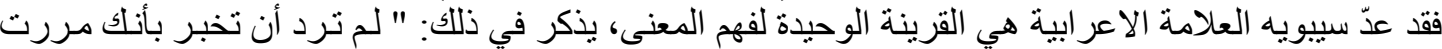

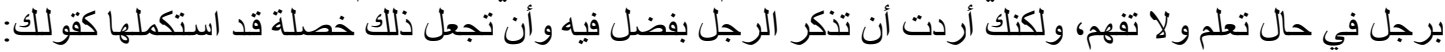

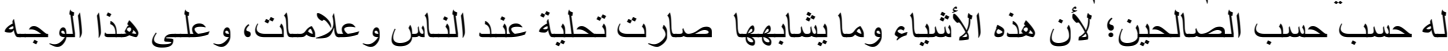

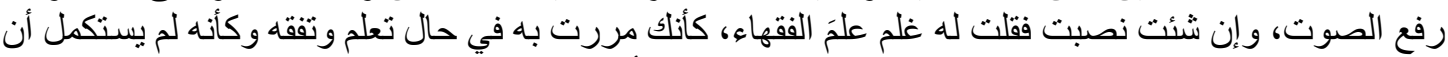

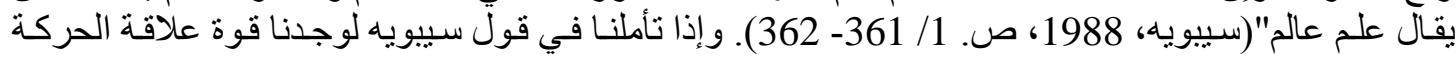

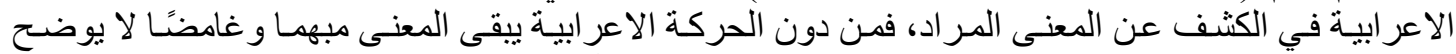

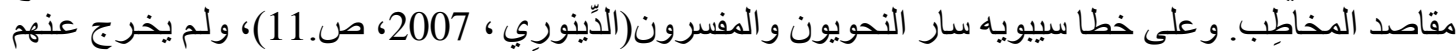

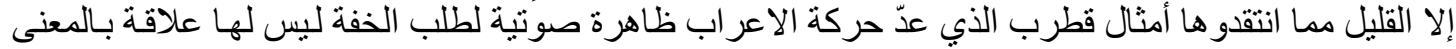

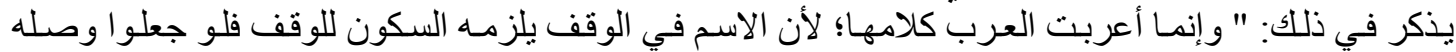

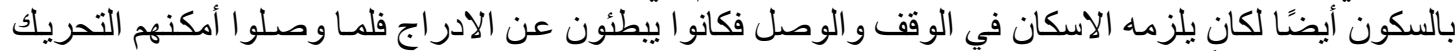

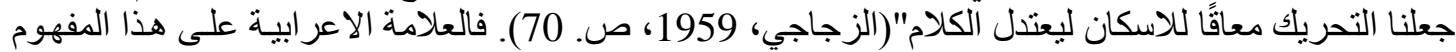

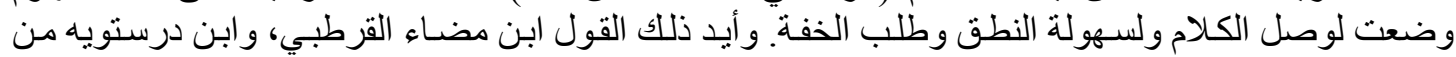

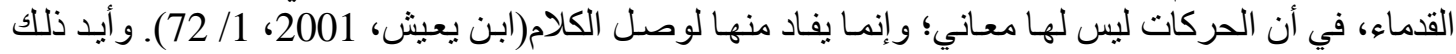

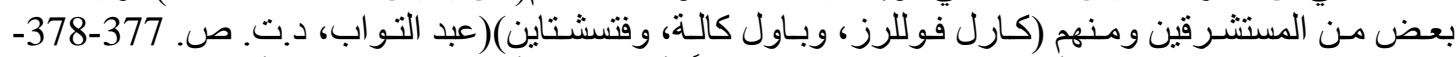

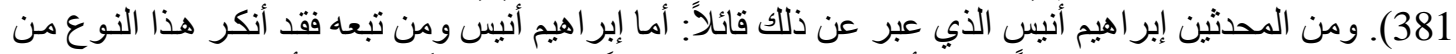

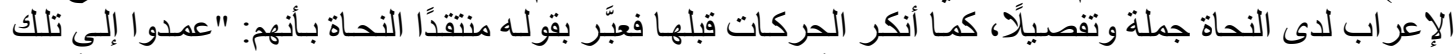

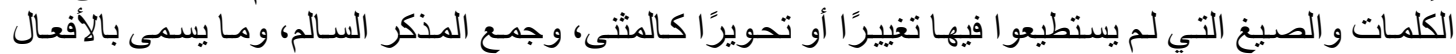

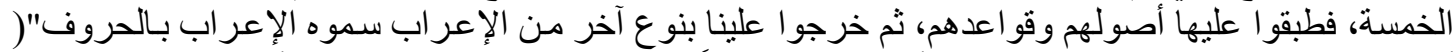

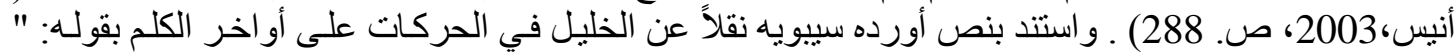

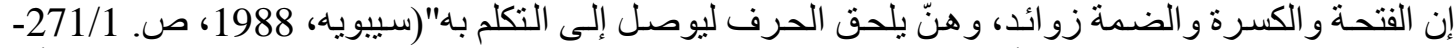

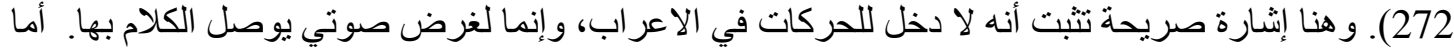

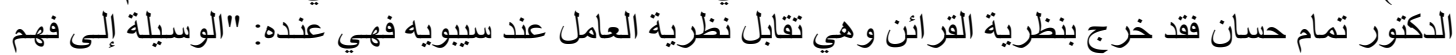

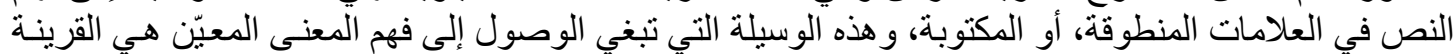




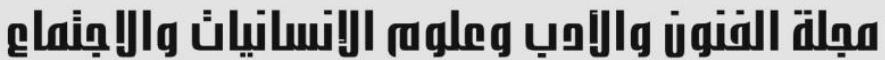

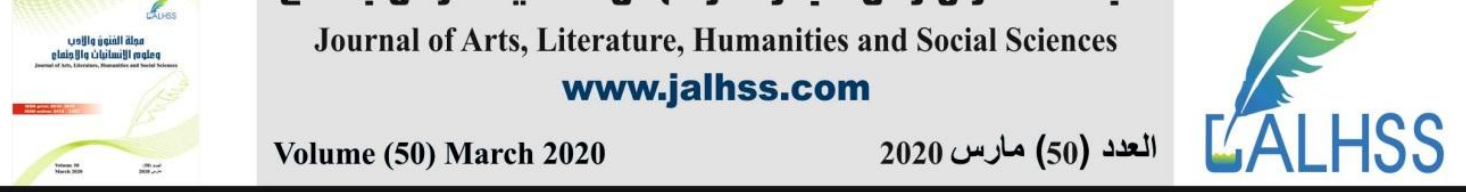

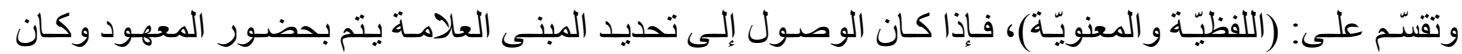

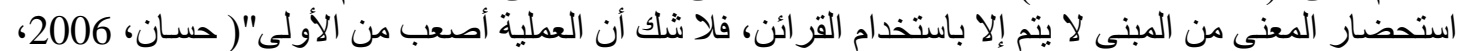

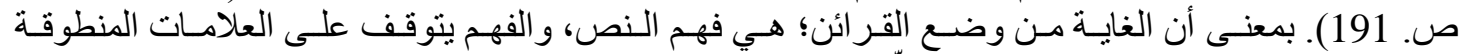

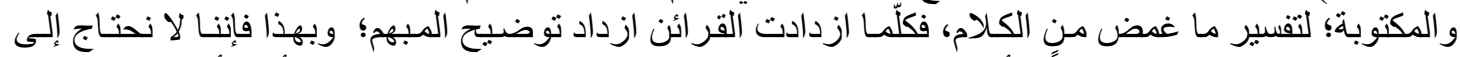

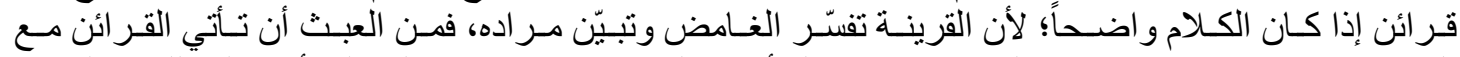

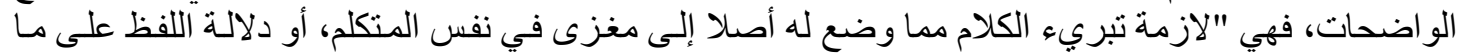

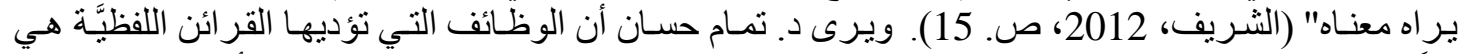

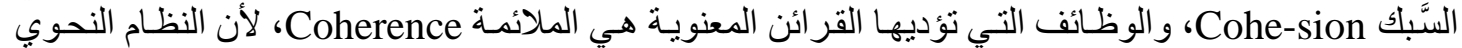

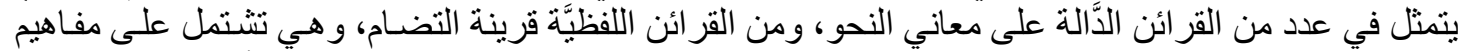

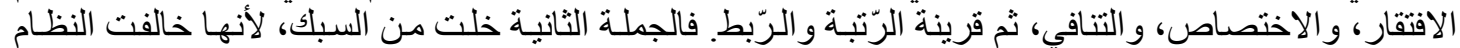

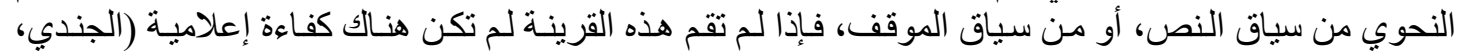

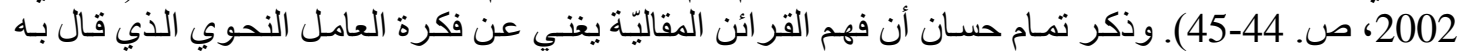

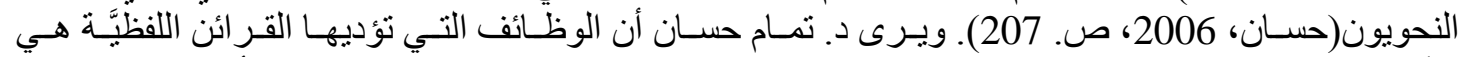

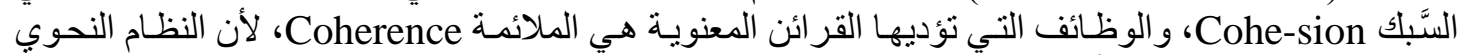

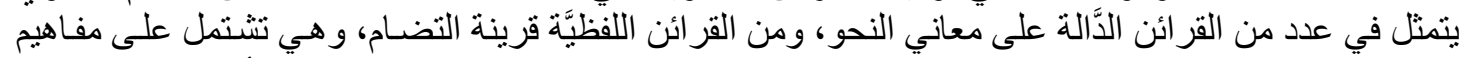

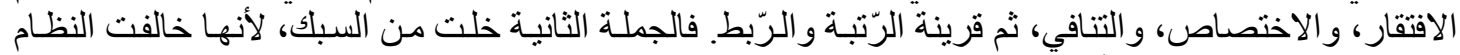

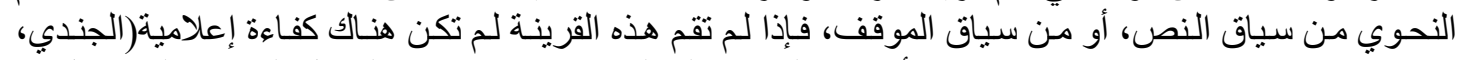

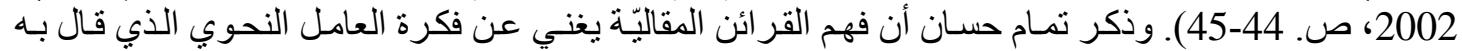

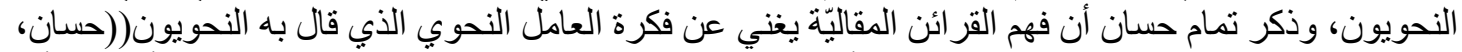

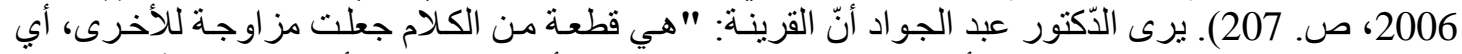

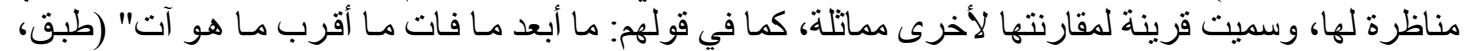

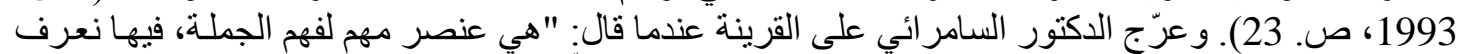

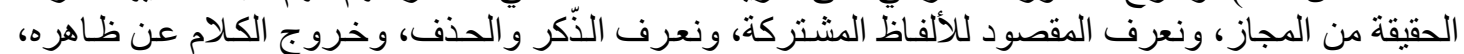

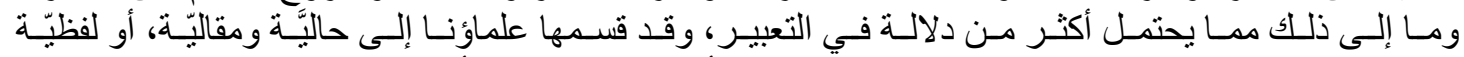

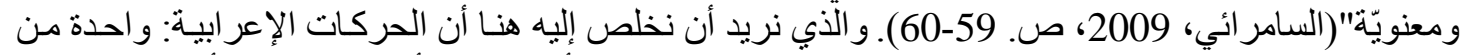

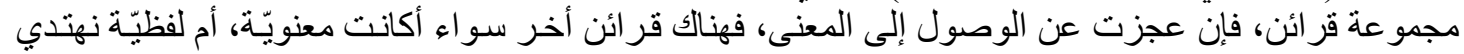

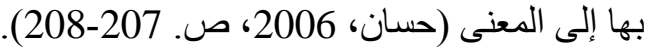

\section{المبحث الثاني \\ مكونات الابداع عند الدكتور تمام حسان}

يتضمن الابداع مجمو عة من القدر ات العقلية تحددها غالبية البحوث و الدر اسات التربوية و النفسية، وهي كالآتي:

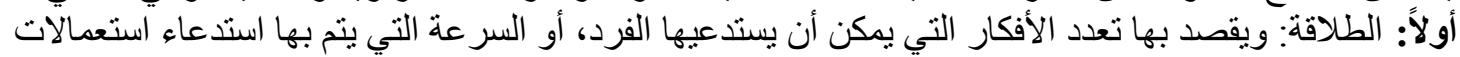

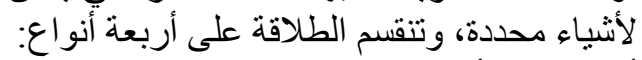

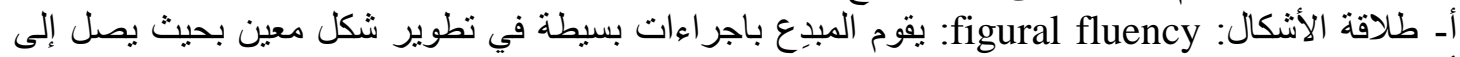

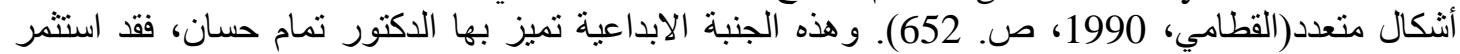

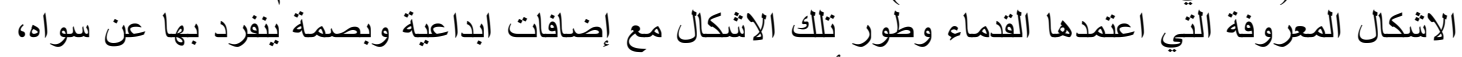

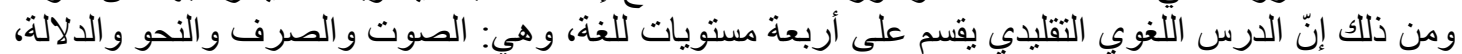

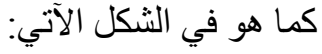




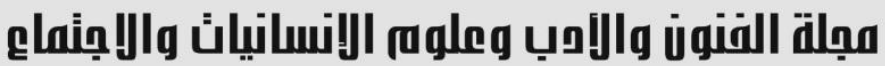

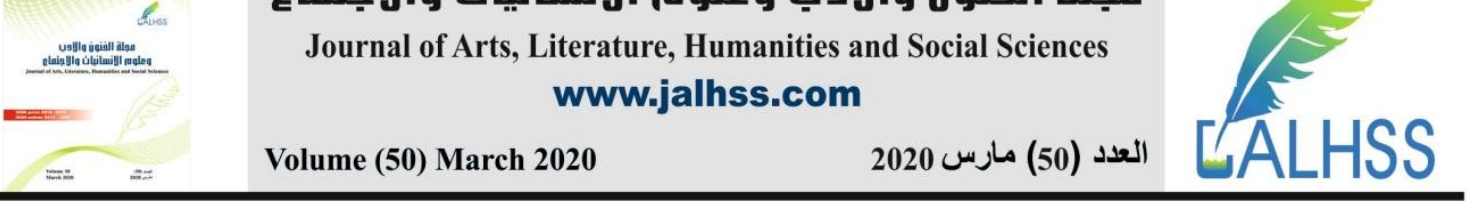

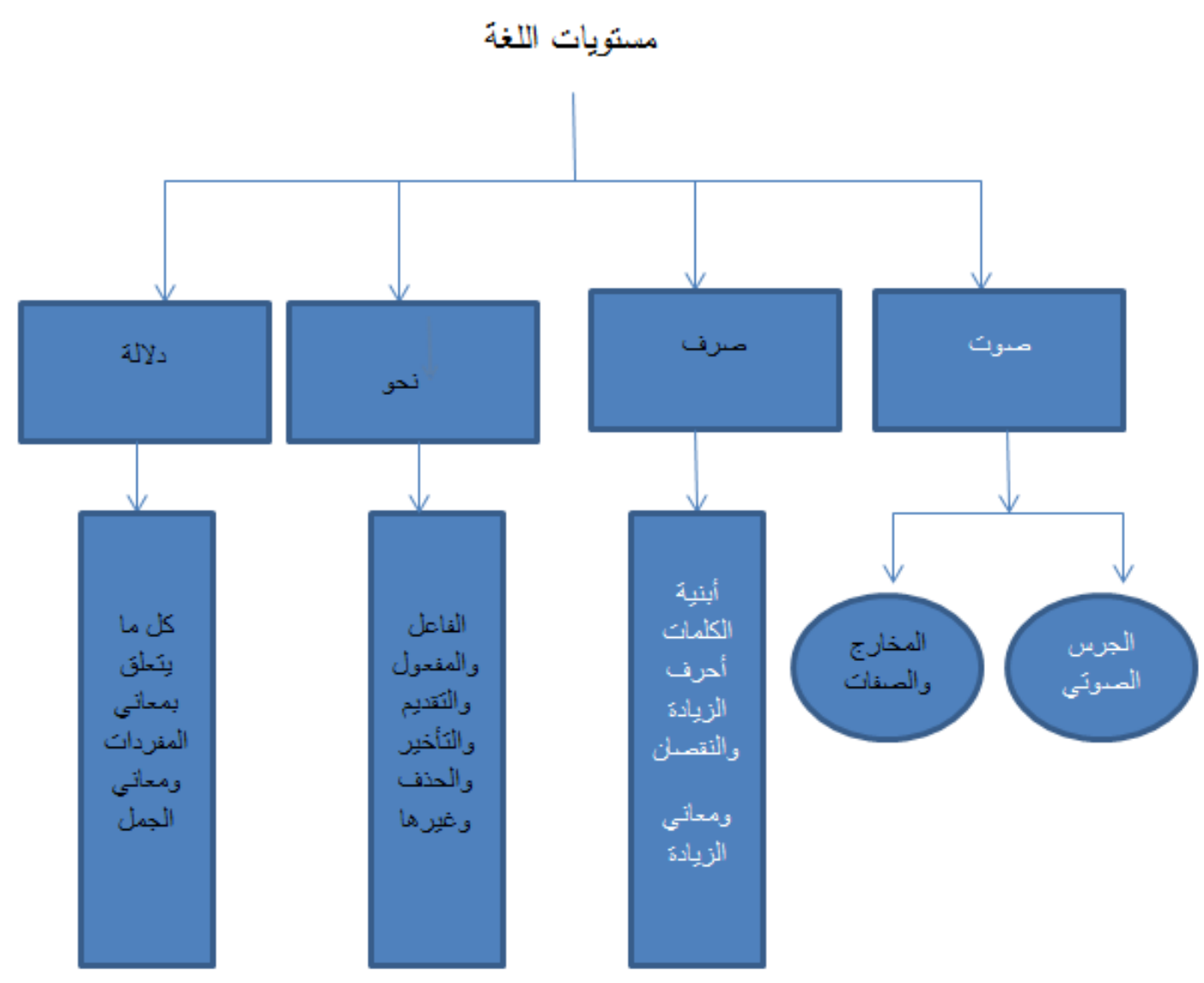

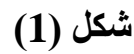

من إعداد الباحث

أما الدكتور تمام حسان فقد قام بتطوير هذا الثكل وقام بتوسيع مطالبه عن طريق أثنكال متعددة كما هو موضح بالثكل الآتي(حسان، 2009، ص. صانط 24). 


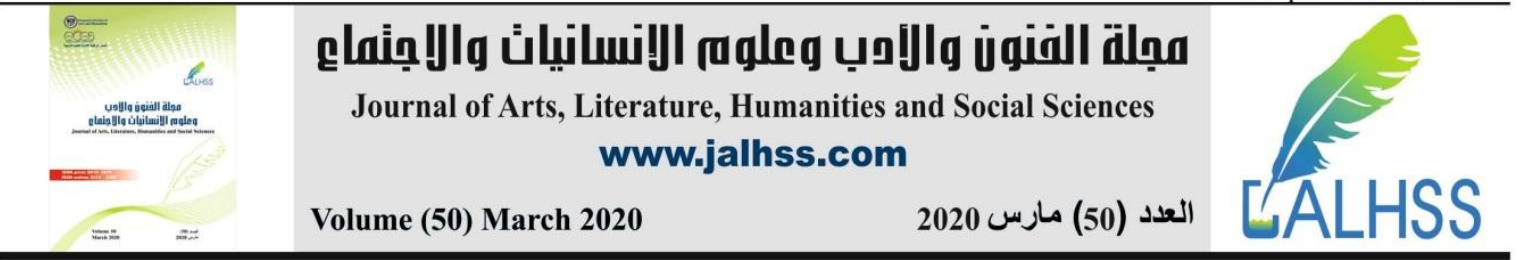

\section{القرينة}

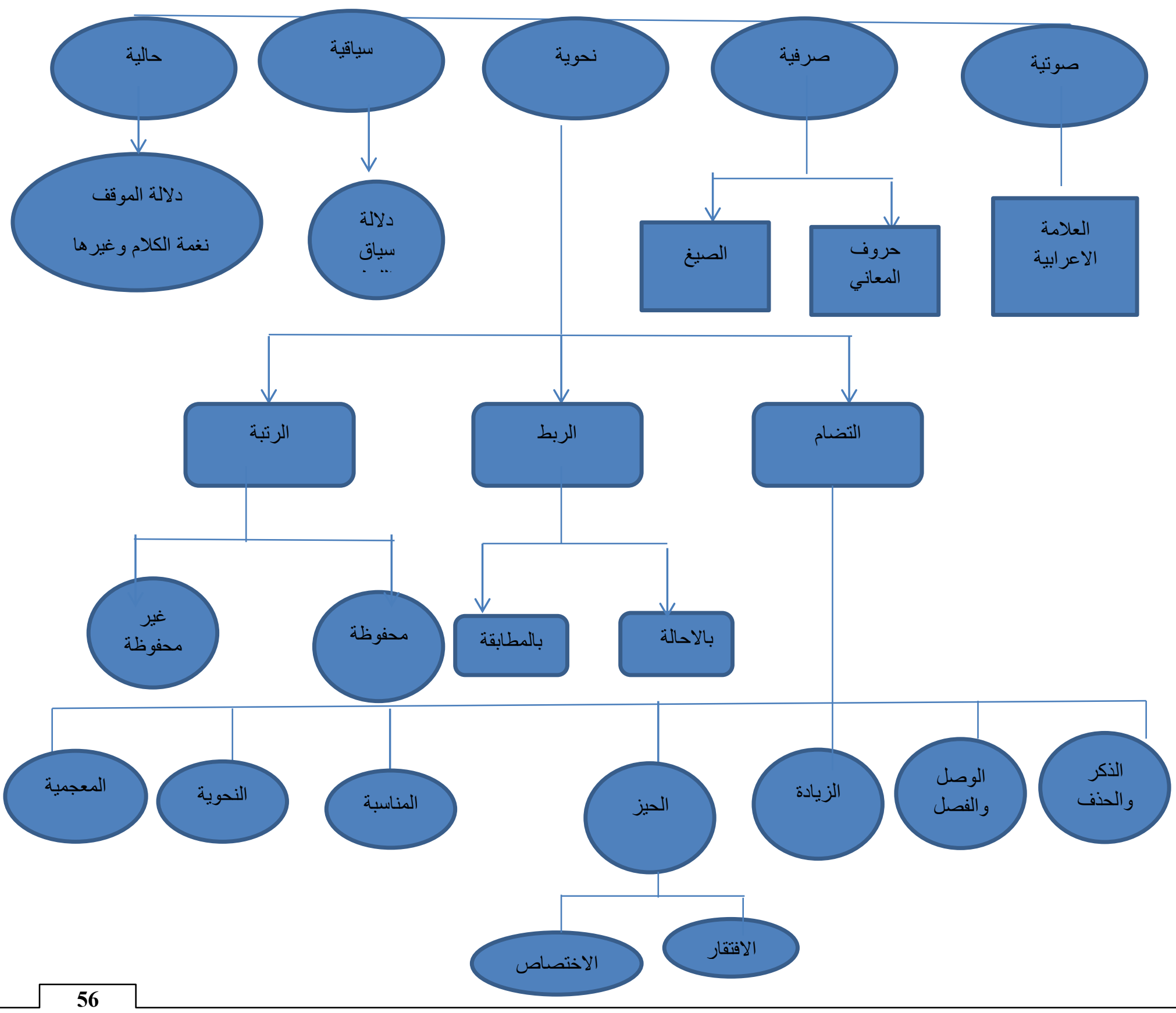




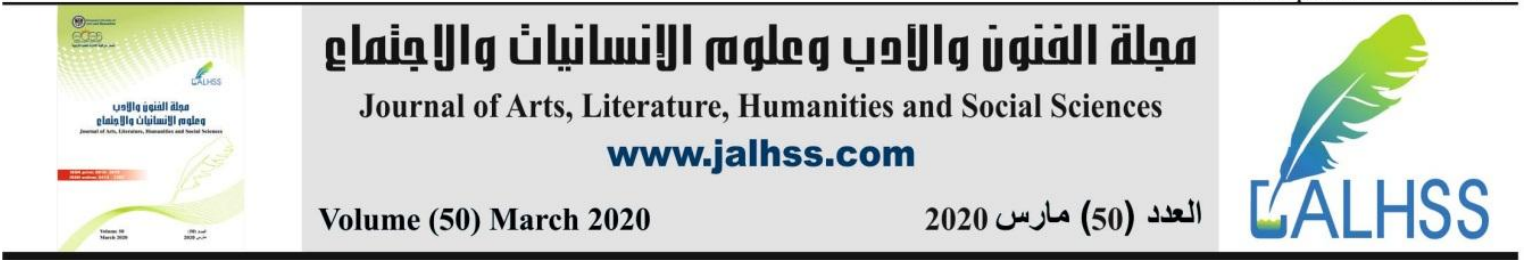

الثكل (2) مخطط

القرينة عند د. تمام حسان

و إذا حللنا هذا الثكل ينضح لدينا بعض الملامح الابداعية والأفكار الجديدة التي تميز بها الدكتور تمام حسان في

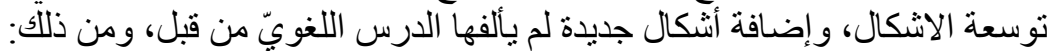

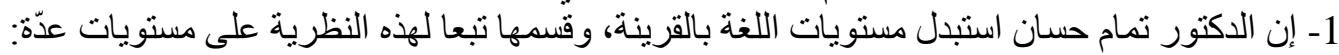

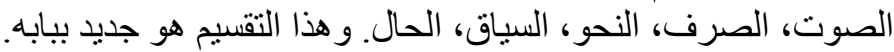

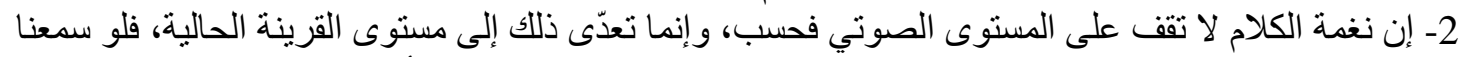

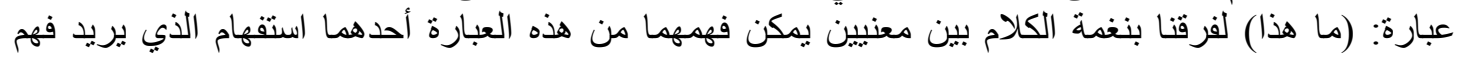

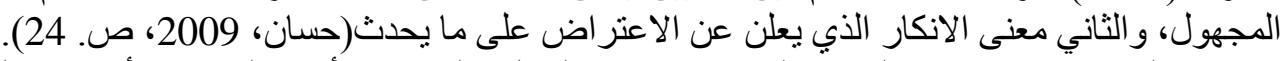

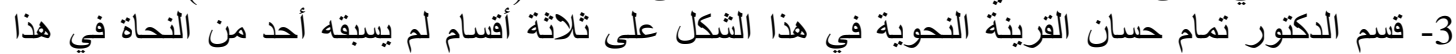

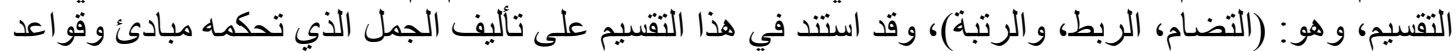
تتوقف عليها إفادة الكلام. فالكلمة في الجملة يغلب أن تتطلب كلمة أخرى تقع في حيزها بشروط خاصة تتصل

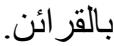

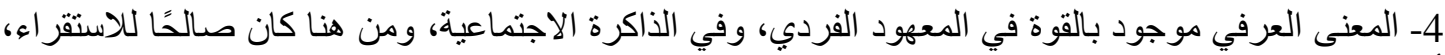

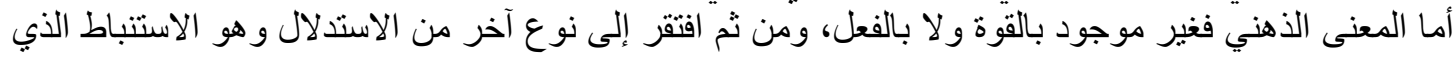

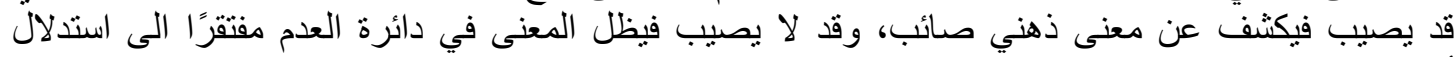

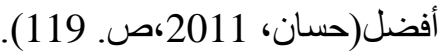

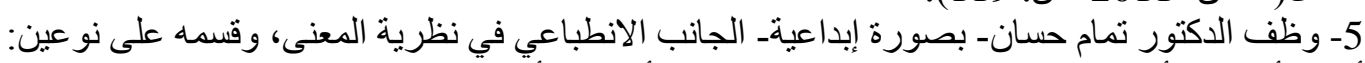

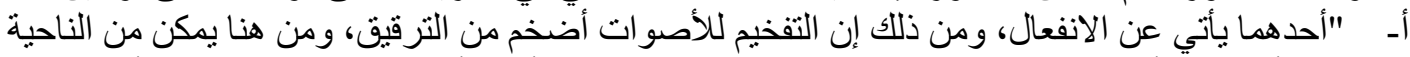

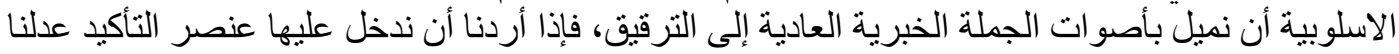

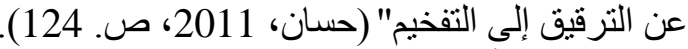

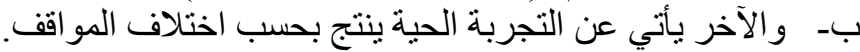

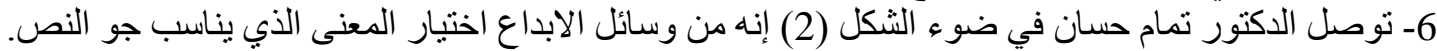

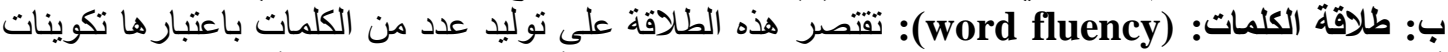

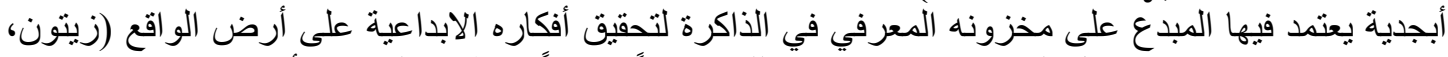

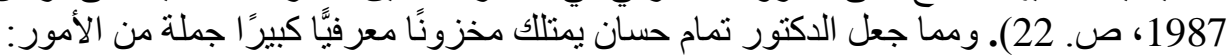

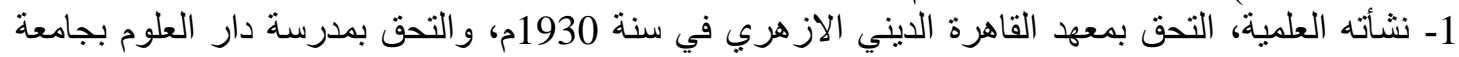

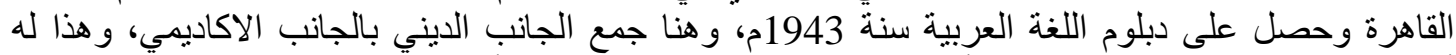

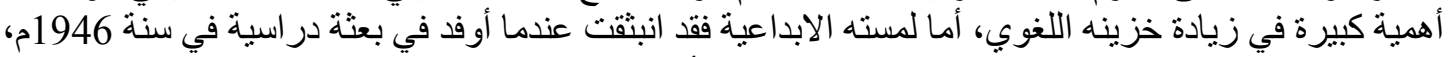

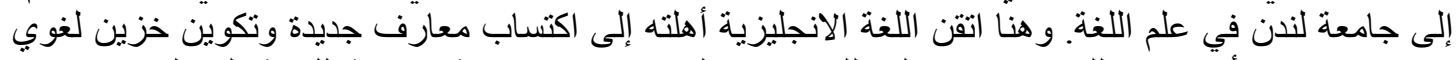
كبير، و لا سيما أنه جمع اللغتين في رسالته للماجستير التي عنونها لإنيا (دراسة صوتية للهجة الكرنك في صعيد

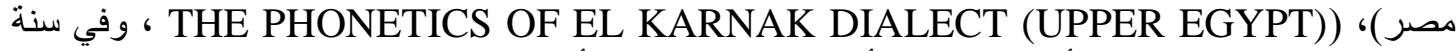

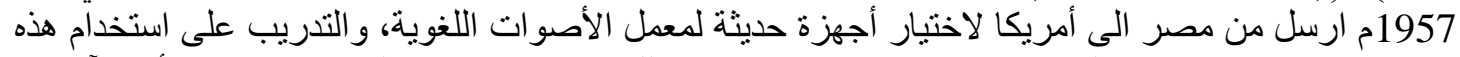

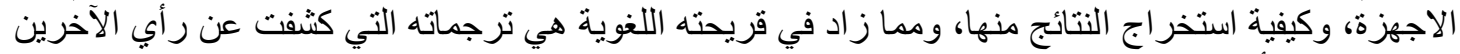

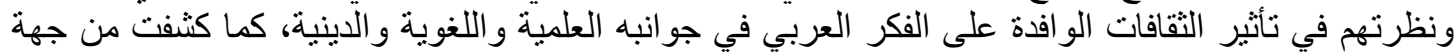

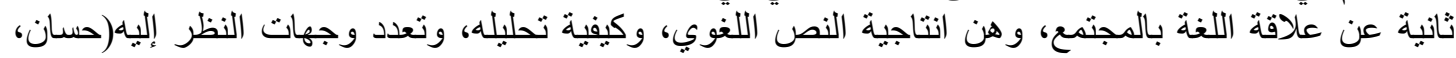




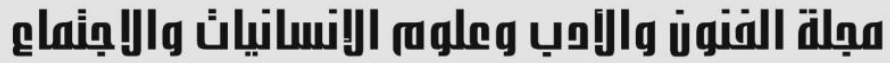

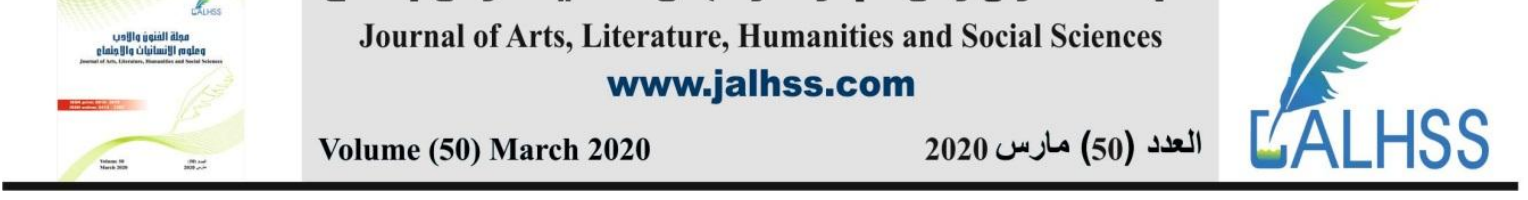

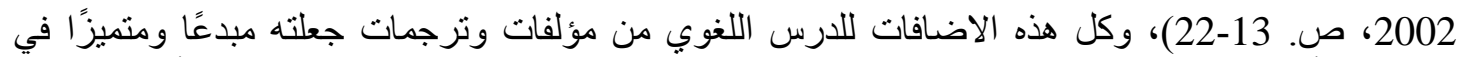

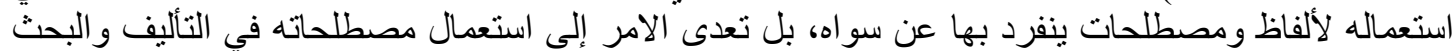

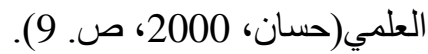

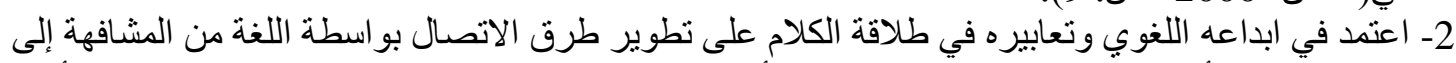

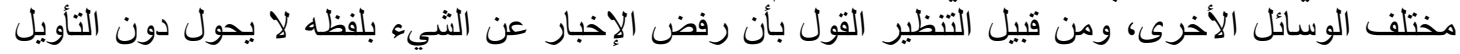

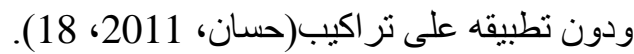
3- اعتمد في كتابه الفكر اللغوي الجديد على التوفئ 18 التوفيق بظلال المعاني في نظرياته بخلاف علماء اللغة القدماء الذين

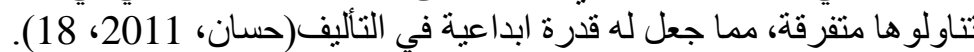

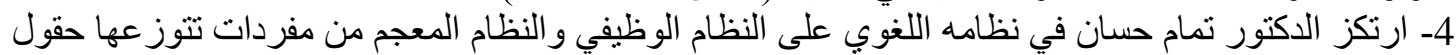

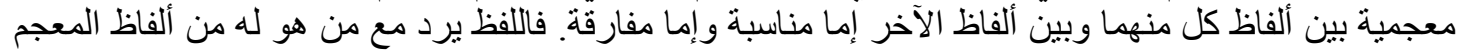

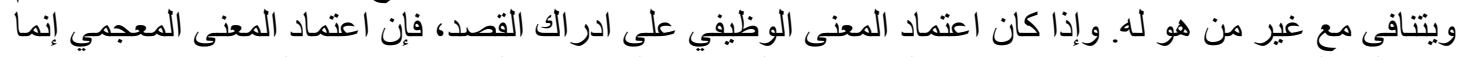

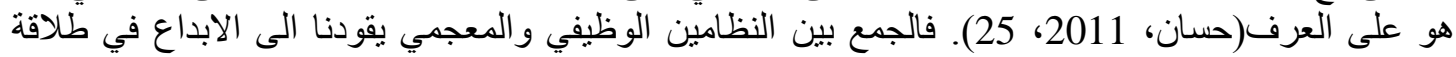
الكلمات.

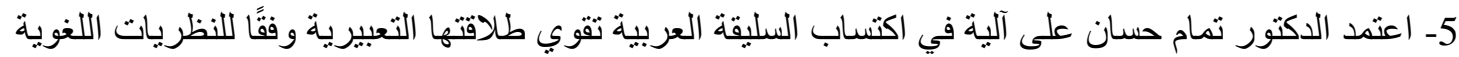

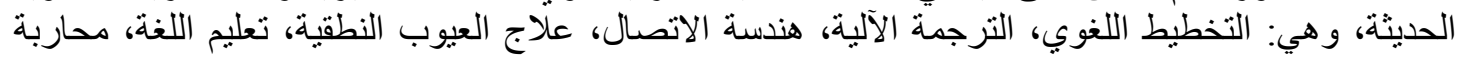

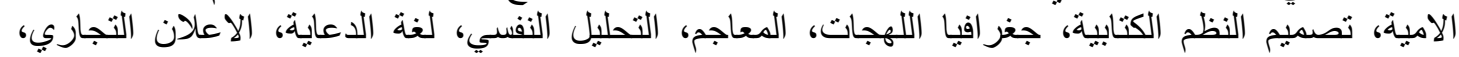

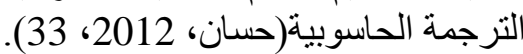

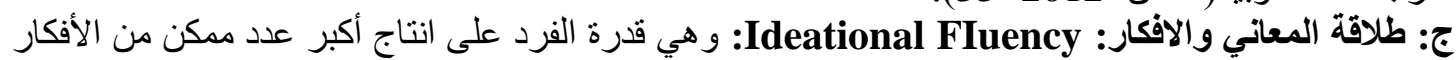

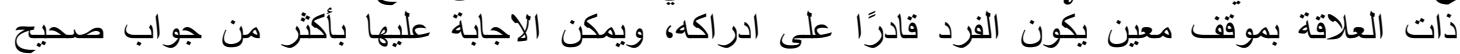

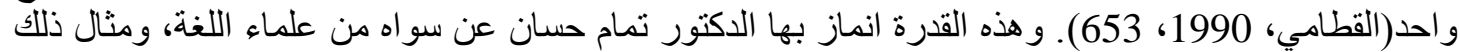

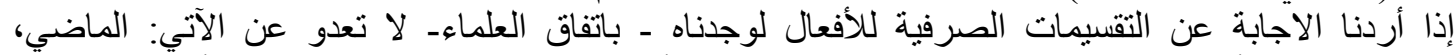

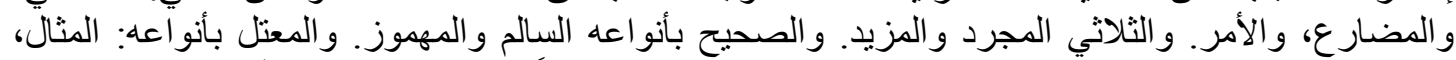

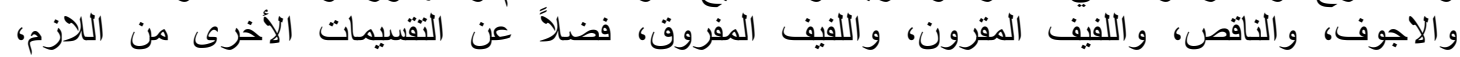

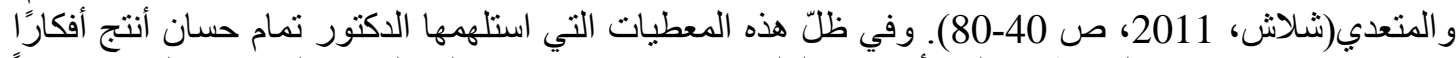

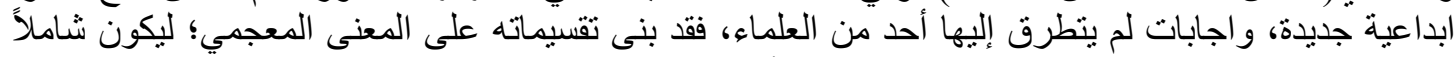

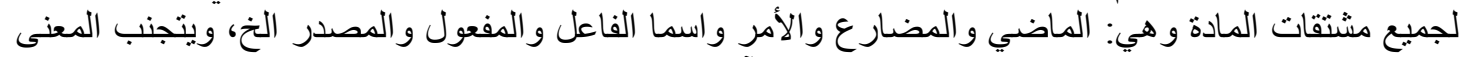
النحوي كالمتعدي واللازم، كالتقسيم المبين في الثنكل الآتي: ( حسان، 2006، 252/2). الفعل

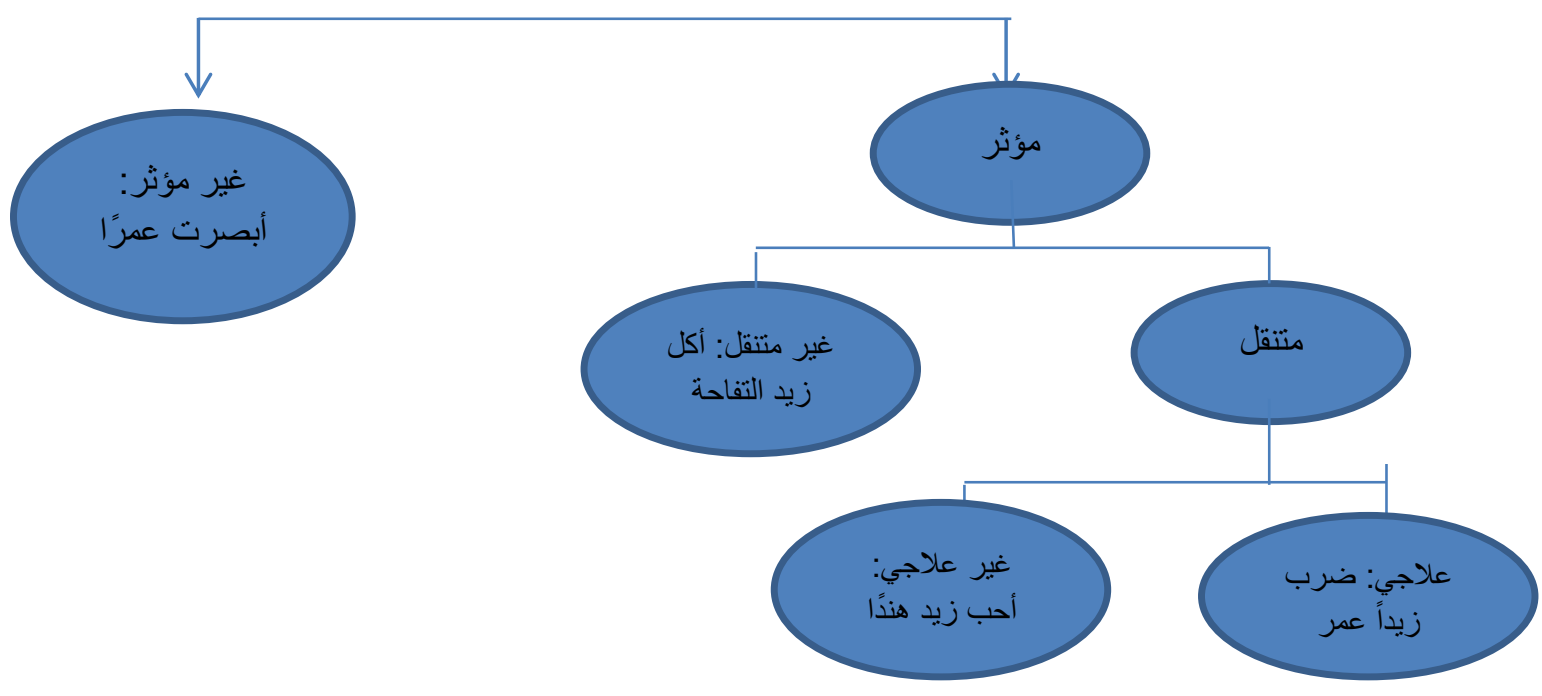




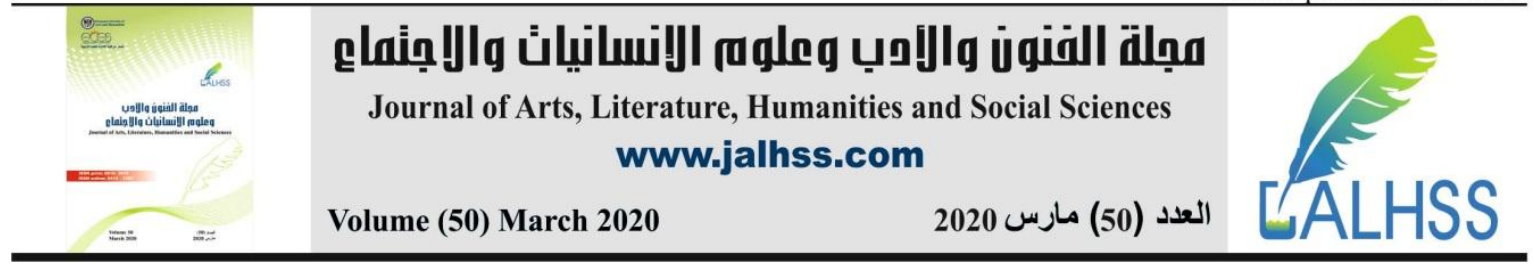

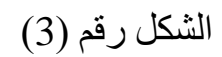

تقسيم الفعل على وفق المعنى المعجمي

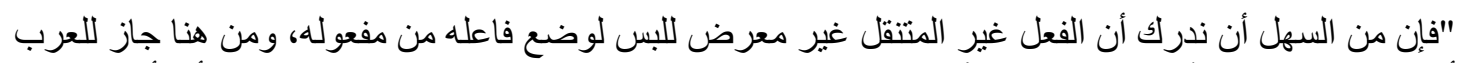

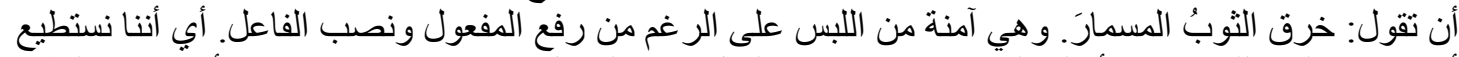

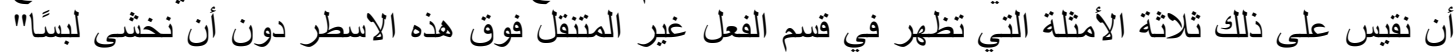

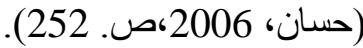
د: الطلاقة التعبيرية: Expressional Fluency: و هي تتضمن التفكير السريع في الكلمات المرتبطة بموقف

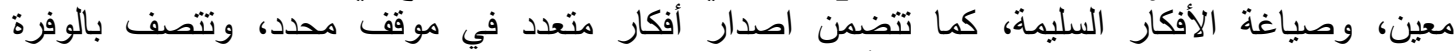
و التتوع(القطامي، 1990، 653). ولعل من أهم الامور الابداعية في باب طلاقة الابداع التعبية التعبيرية عند الدكتور

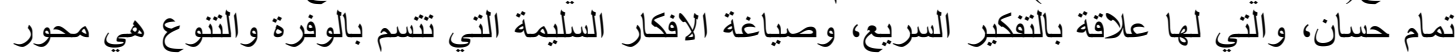

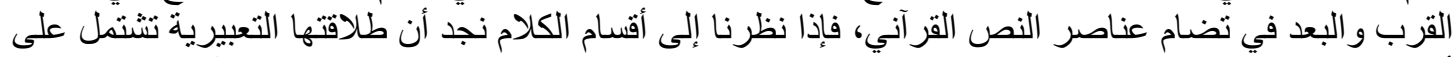

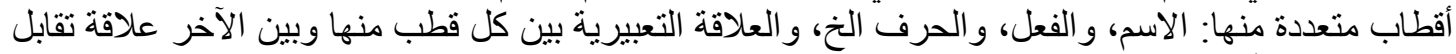

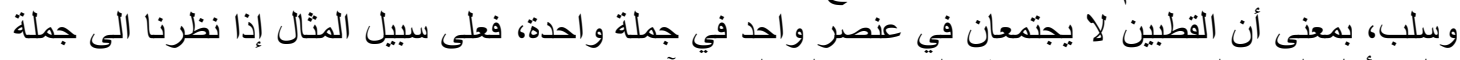
مثل: (أكل الغلام التفاحة) وجدنا تقاطع المحاور التين على النحو الآتي:

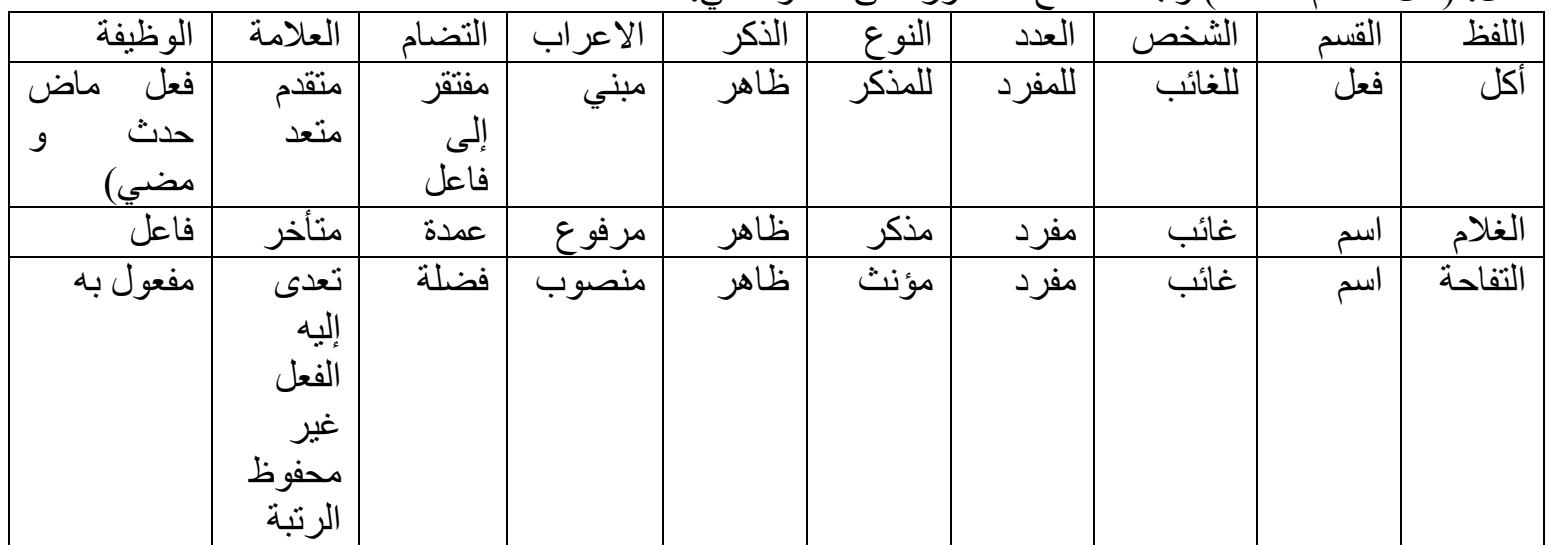

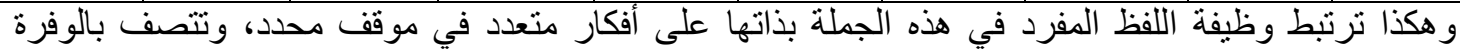

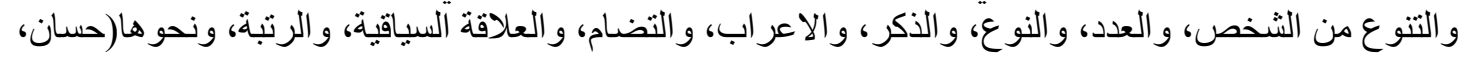

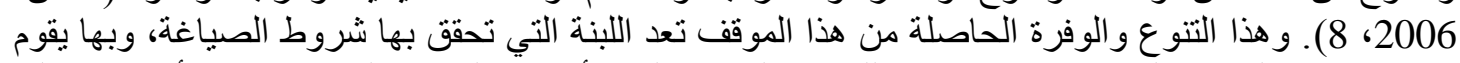

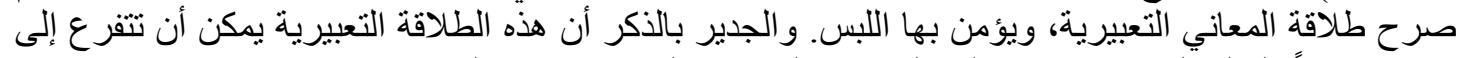

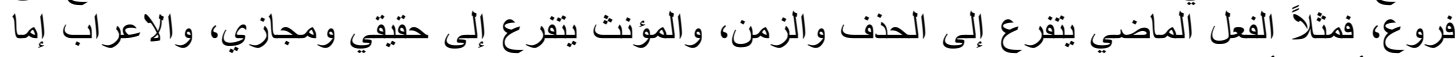
علامة أصلية أو فرعية.

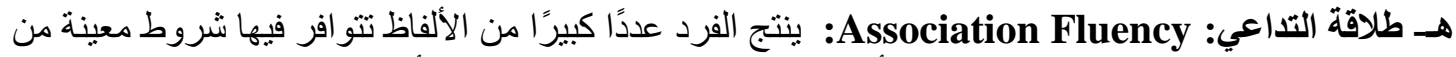

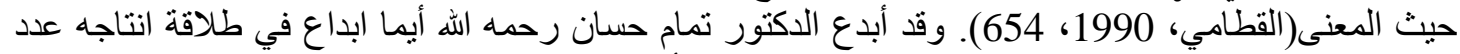

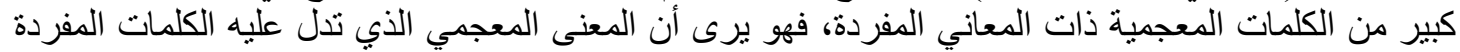

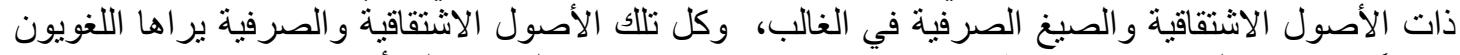

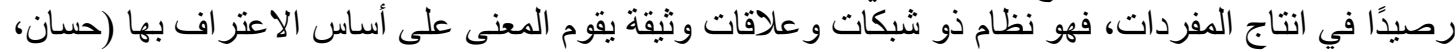

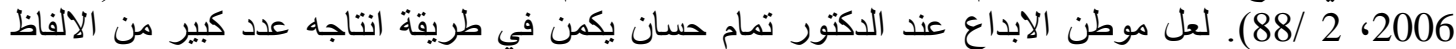

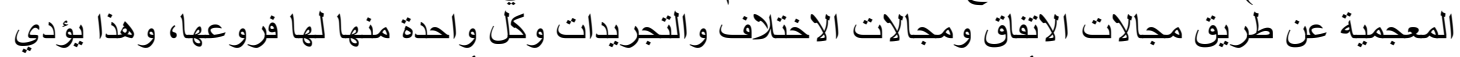

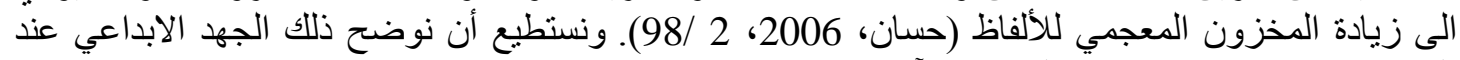
الدكتور تمام حسان عن طريق المخطط الآتي:

نظام المعجم 

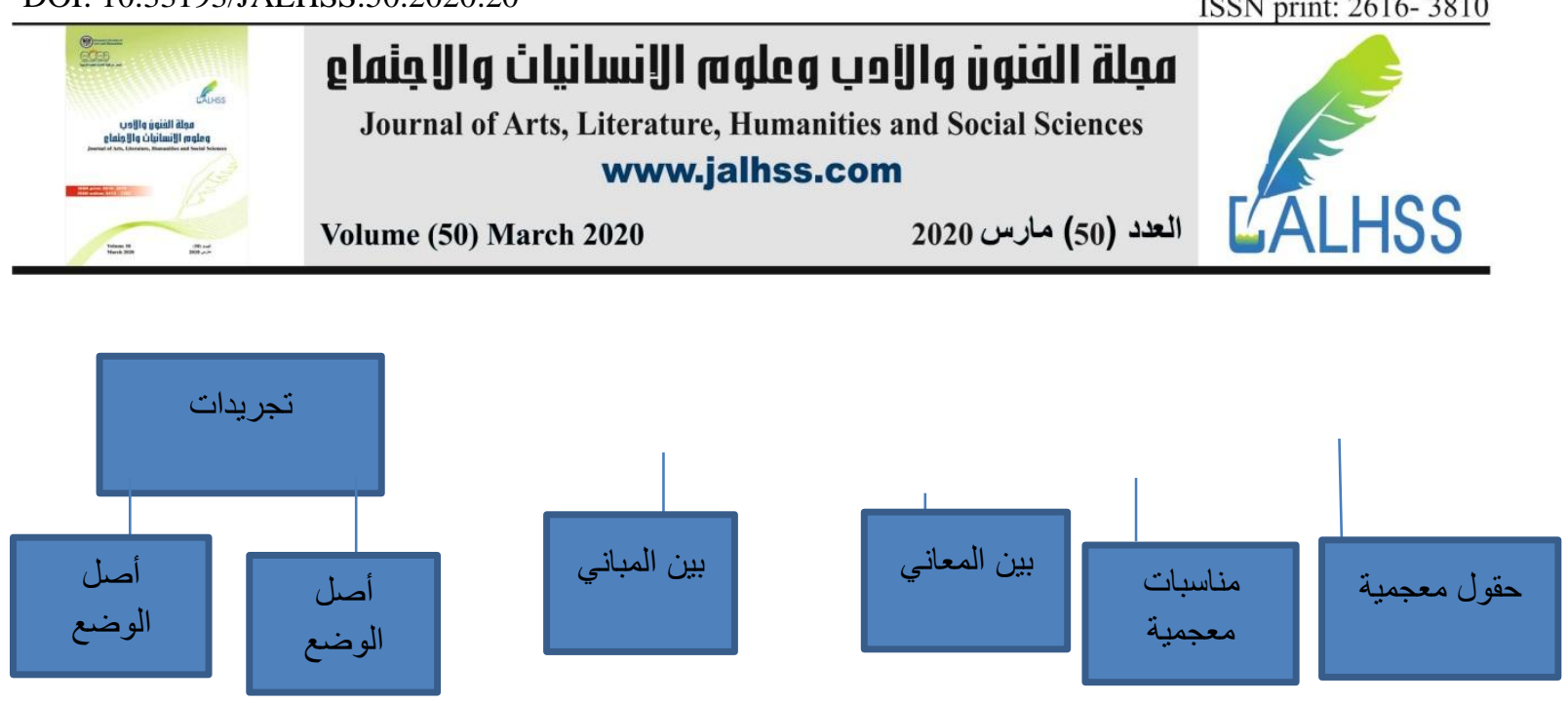

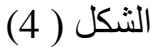

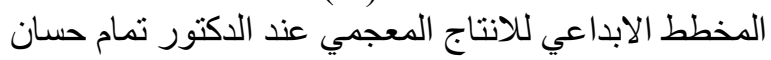

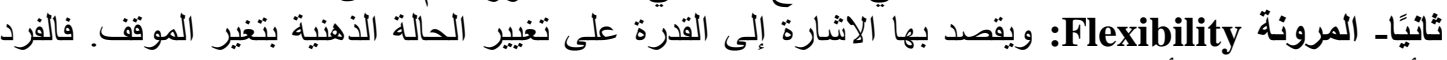

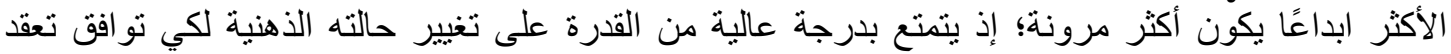

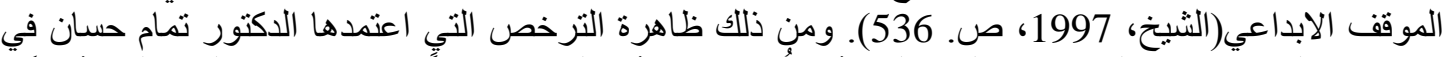

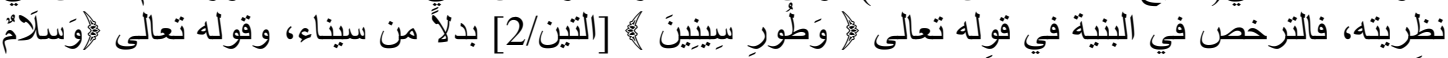

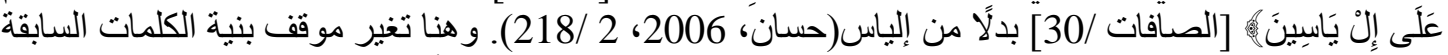

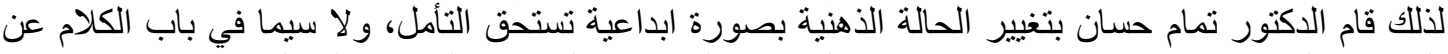

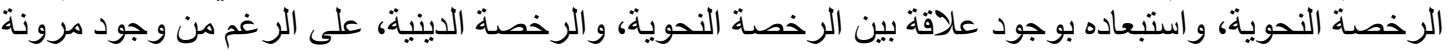

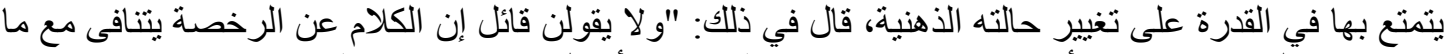

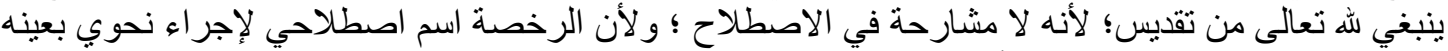

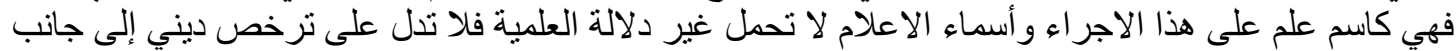

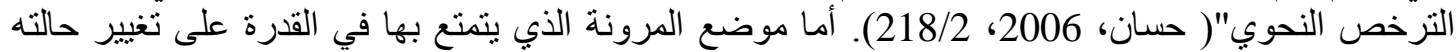

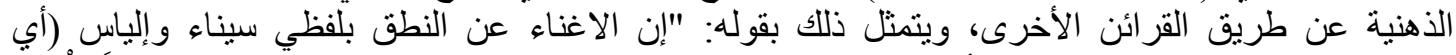

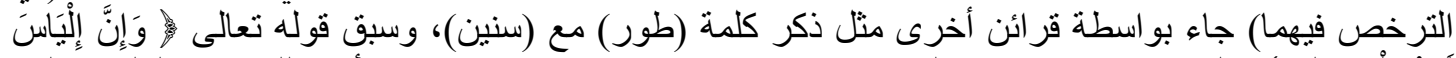

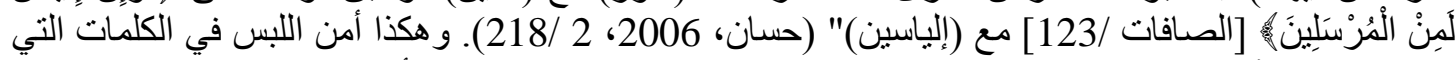

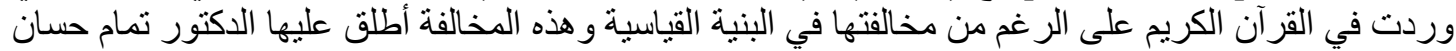

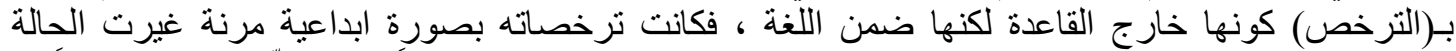

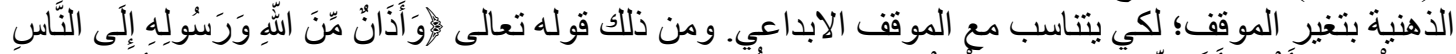

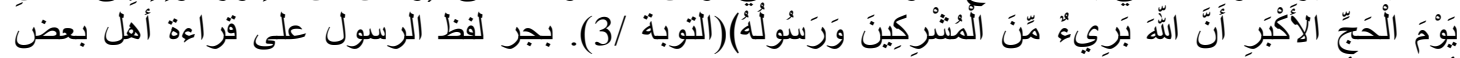

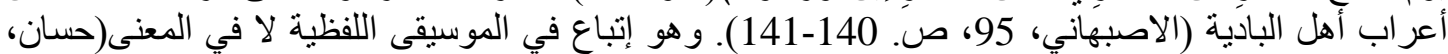

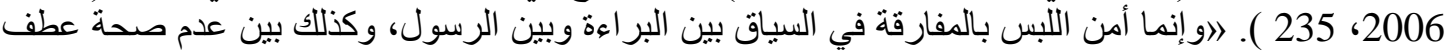
الرسول على المشركين لانتفاء الجامع.

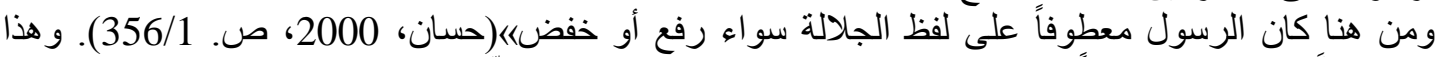

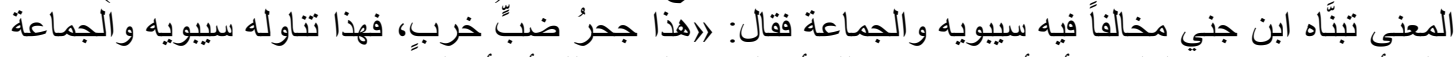

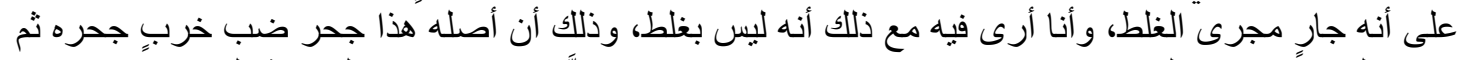

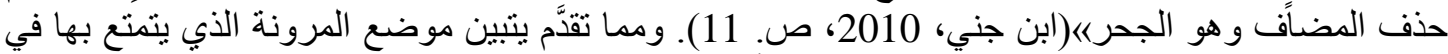

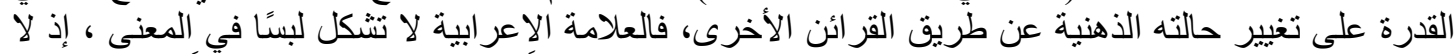

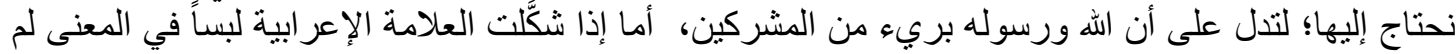

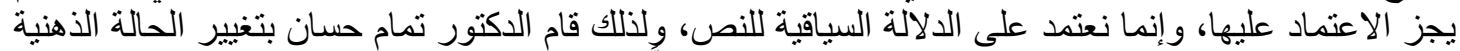

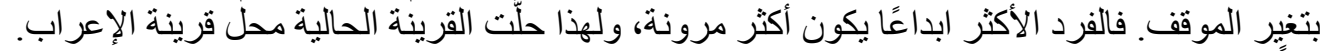

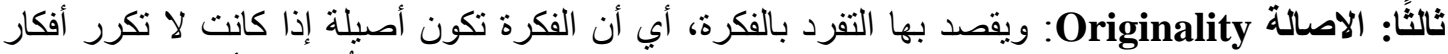

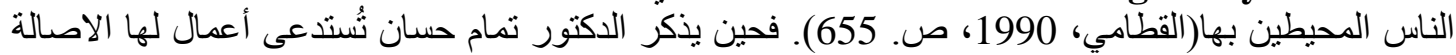

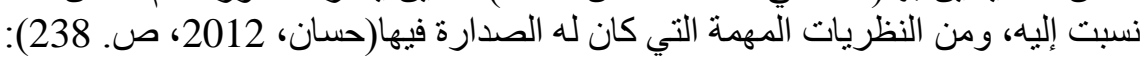




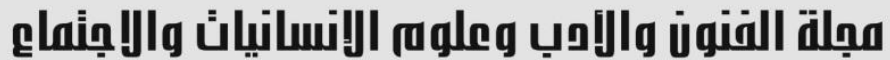

Journal of Arts, Literature, Humanities and Social Sciences

\section{www.jalhss.com}

- إنه أول من استنبط موازين التنغيم وقو اعد النبر في اللغة العربية، حيث لم تكن مدروسة قبله وكانت تدرس

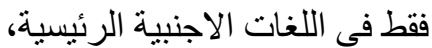

- كانت له الأصالة في در اسة (المعجم) باعتباره نظامًا لغويًّا متكاملاً.

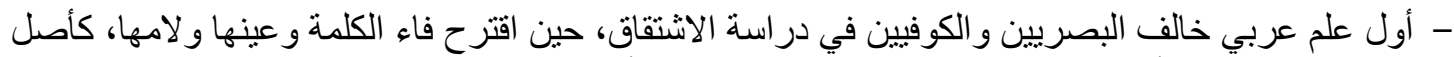

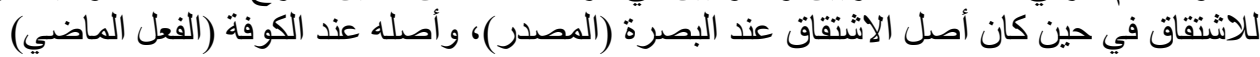

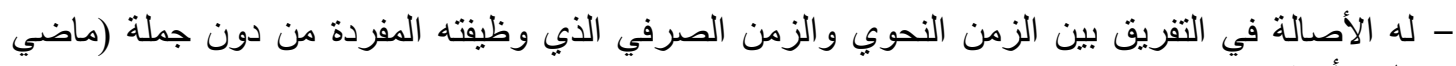

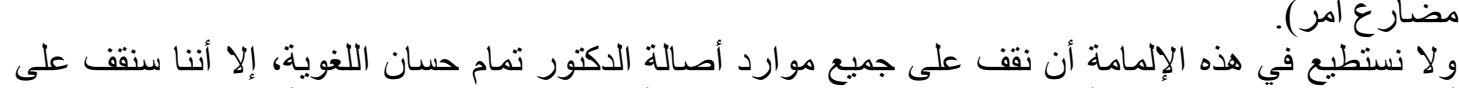

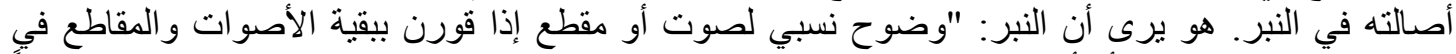

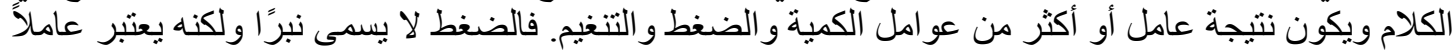

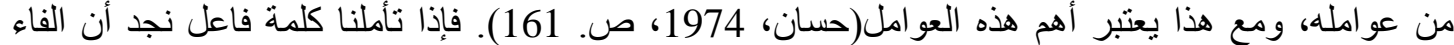

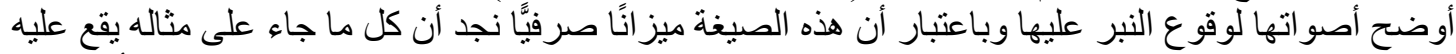

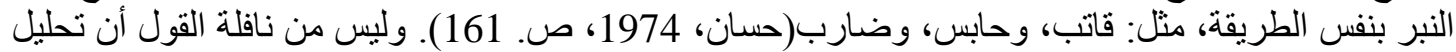
الدكتور تمام حسان للنبر لها الأصالة والتفرد بالفكرة، فهي لا تكرر أفكار الناس المحيطين بها. وله الأصالة أيضًا

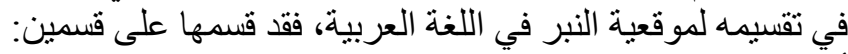

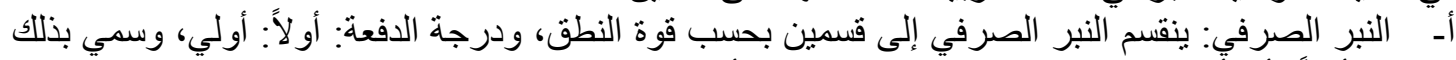

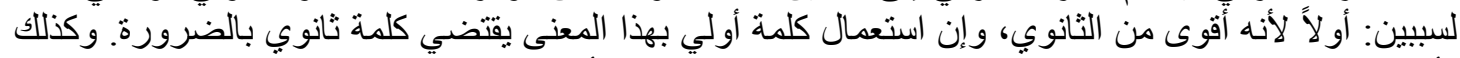

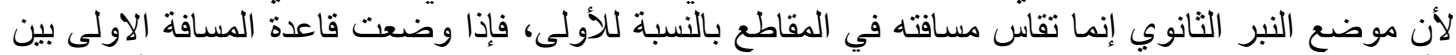

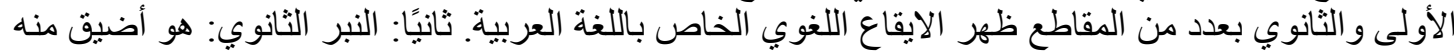

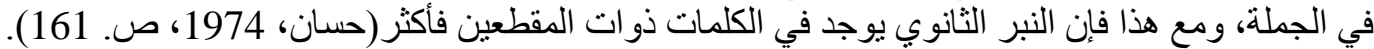

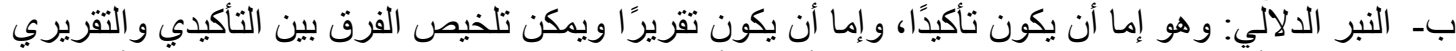

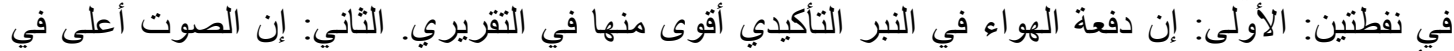

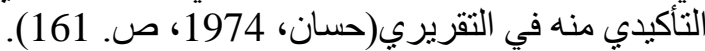

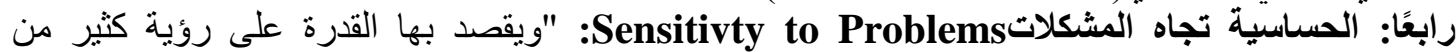

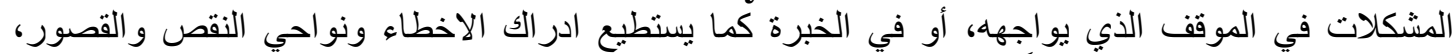

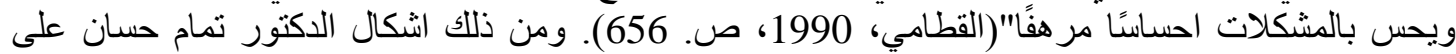

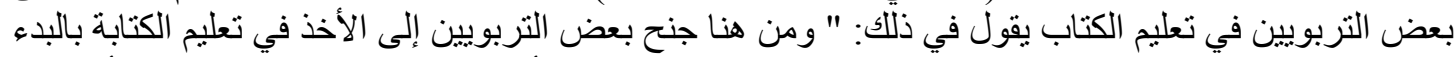

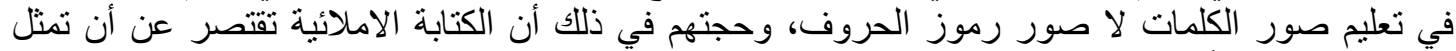

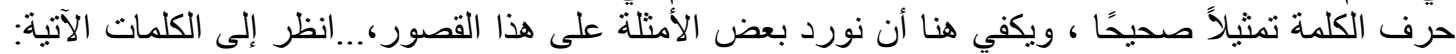

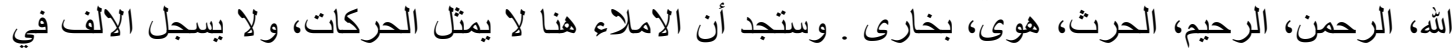

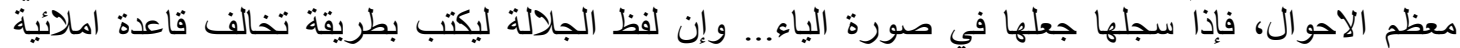

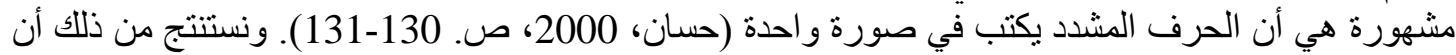

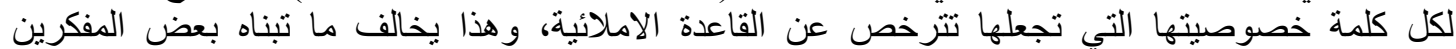

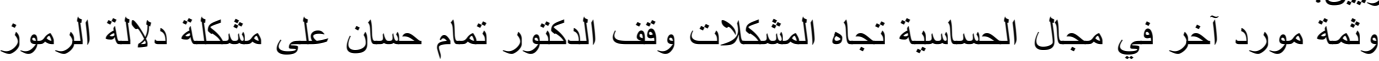

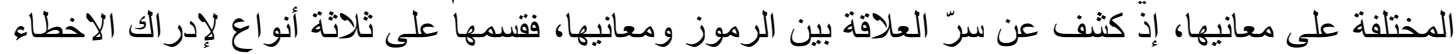

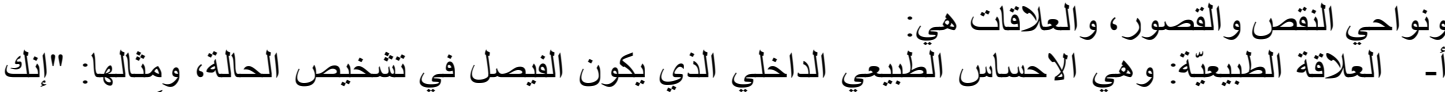

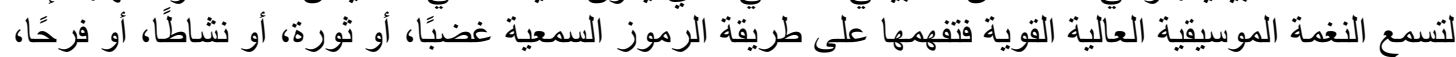

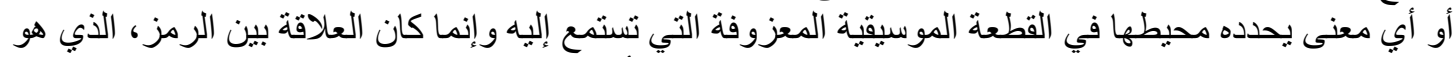

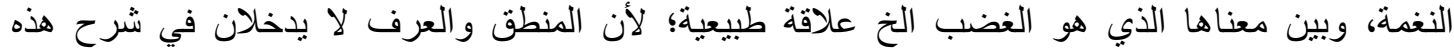

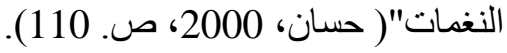




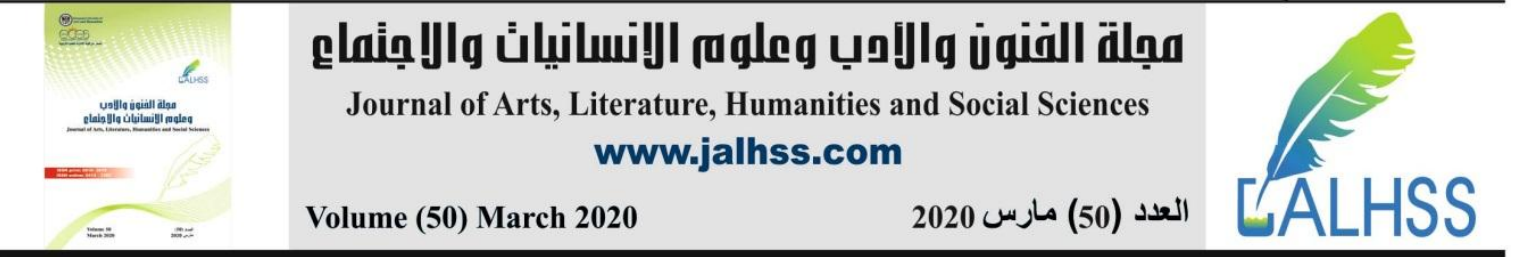

بـ العلاقة المنطقية: وهي اشار ات أو دلالات يتوصل إليها المتلقي عن طريق التفكير المنطقي الذهني(حسان،

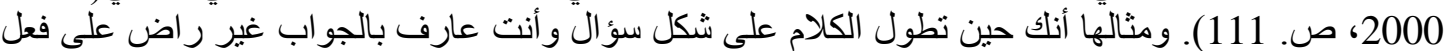

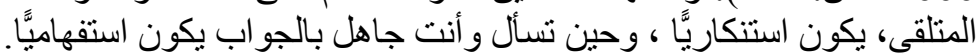

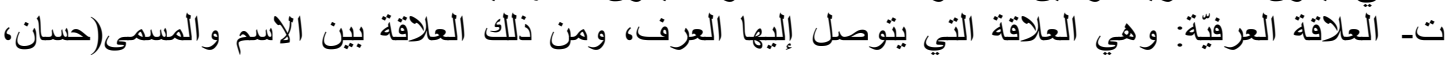

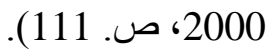

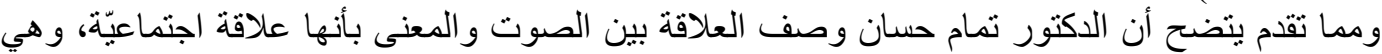

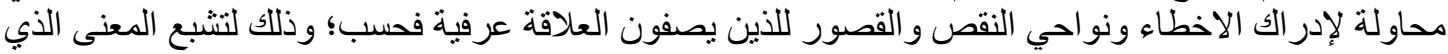

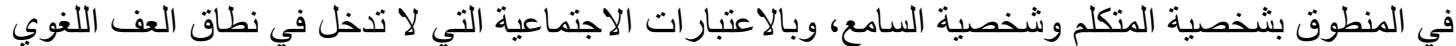

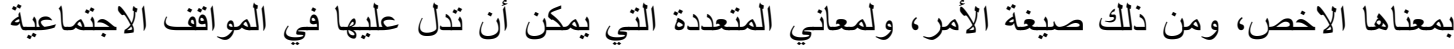

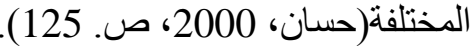

خامسًا: التفاصيل: Elaboration: وتتضمن الخبرة أو المعرفة في مجالات أكثر تفصيلاً، فتعدد الخبرات

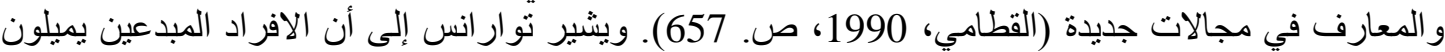

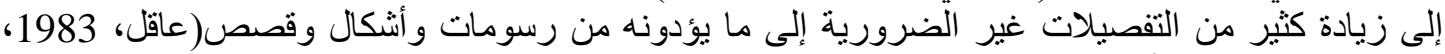

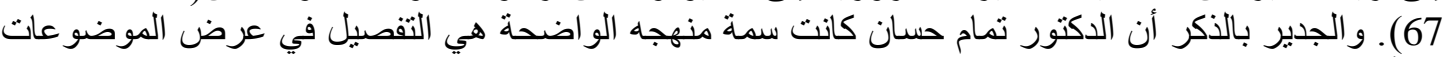

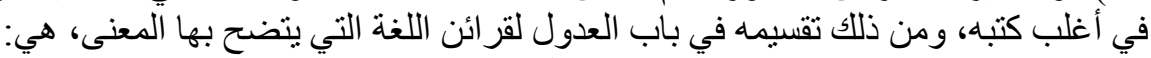

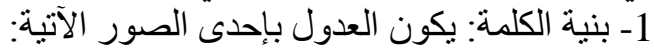

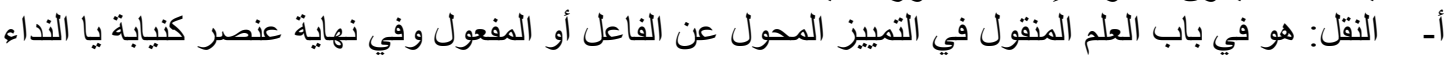

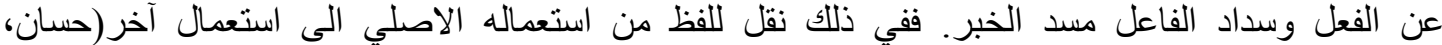

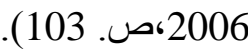

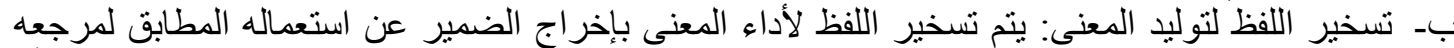

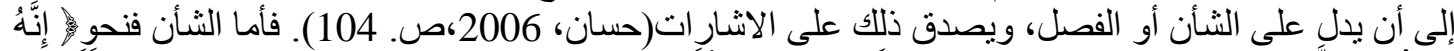

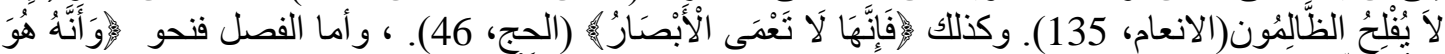

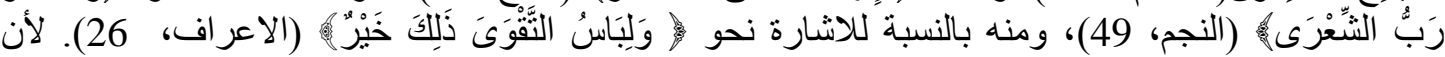

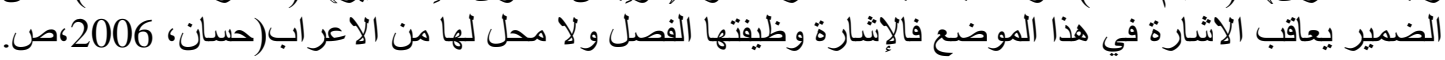

2- الاعراب: يعدل عن الاعراب عدولاً مقبولاً بواسطة ما يسمى (إعراب الجوار)، ومن ذلك قول امرئ

$$
\begin{aligned}
& \text { كأن ثبيرًا في عر انين وبله كبيرُ أناس في بجاد مزملِ } \\
& \text { القيس(الزوزني، د.ت، صدل صن الاعراب 98): }
\end{aligned}
$$

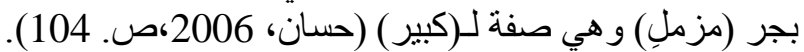
3- الربط: يتم العدول عن الربط في ما بأني:

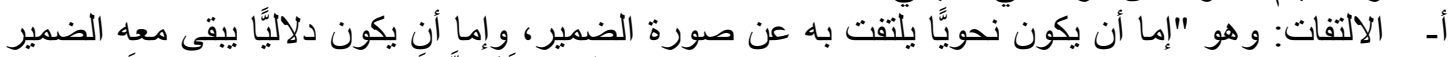

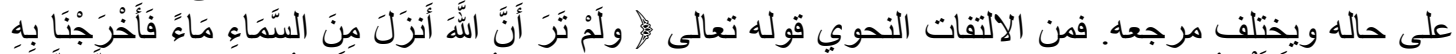

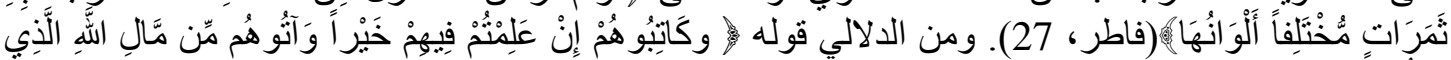

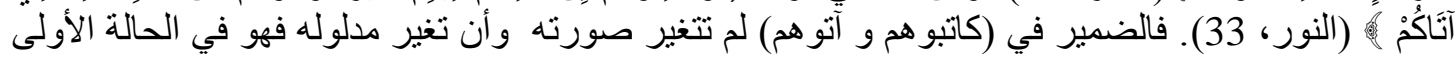

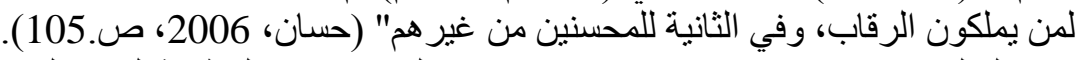

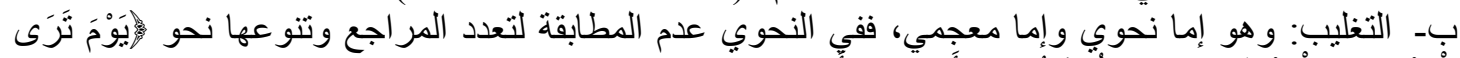

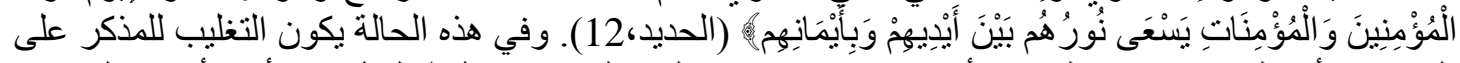

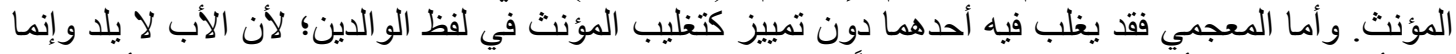

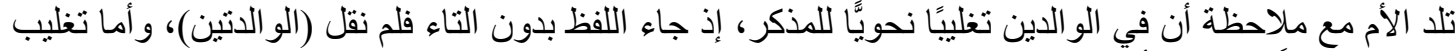

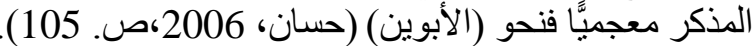

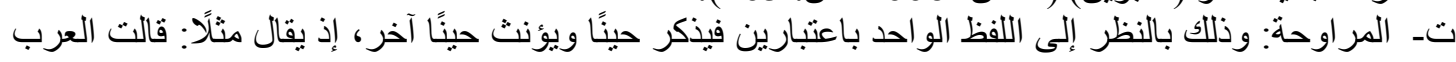

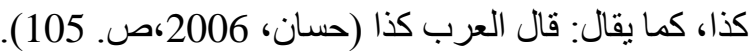




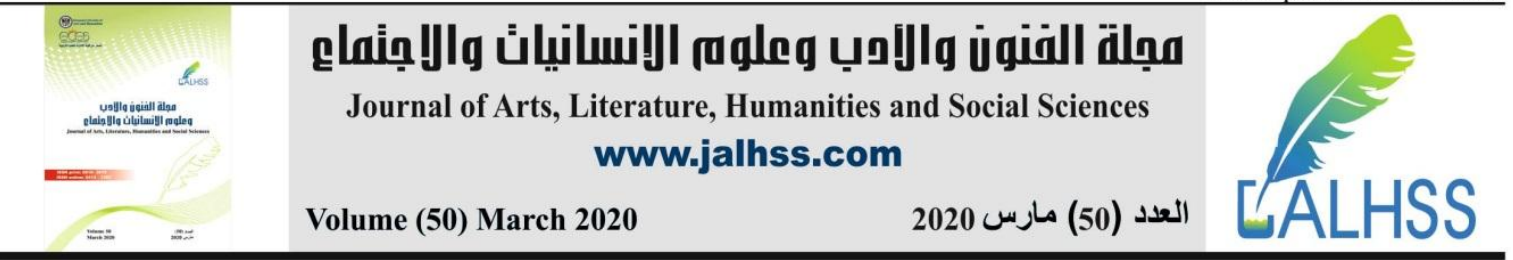

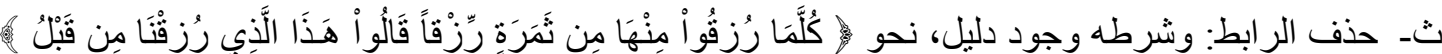

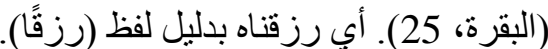

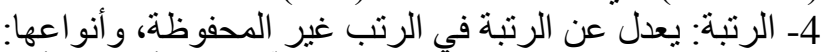

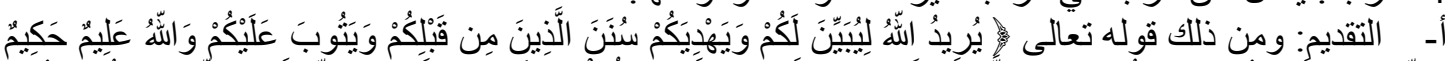

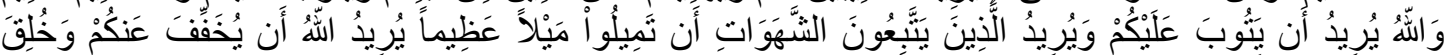

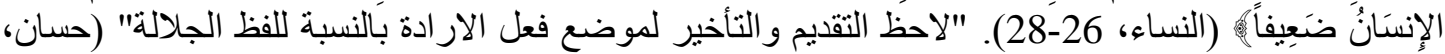

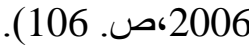

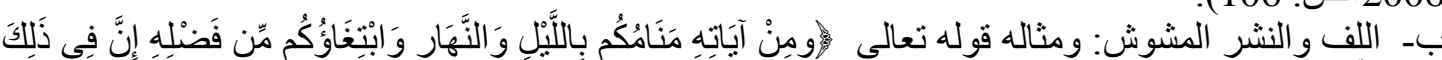

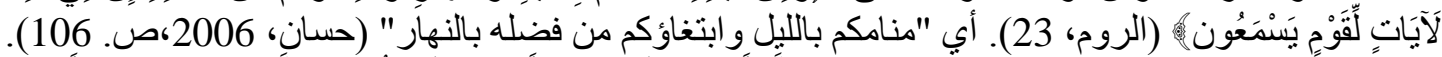

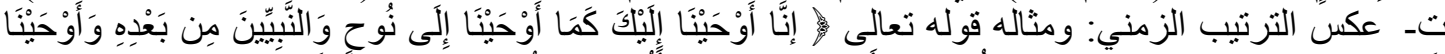

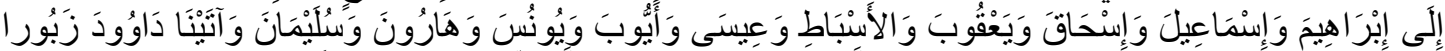

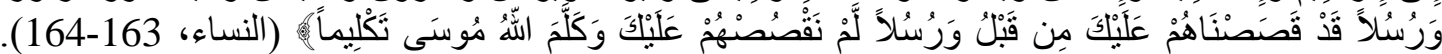

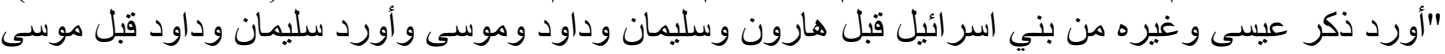

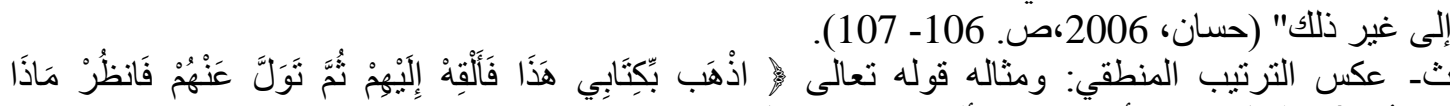

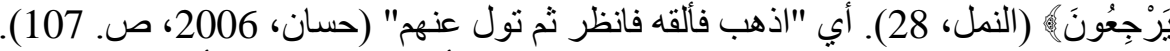

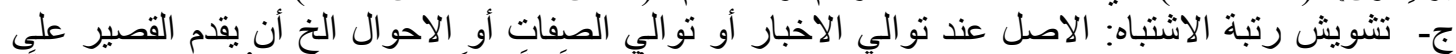

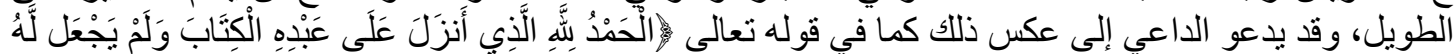

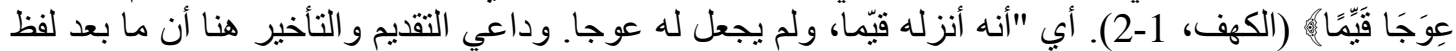

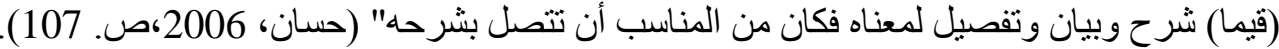

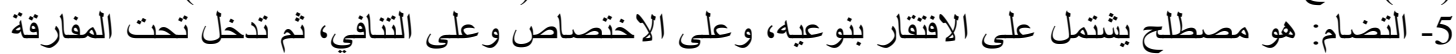

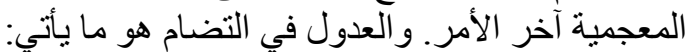

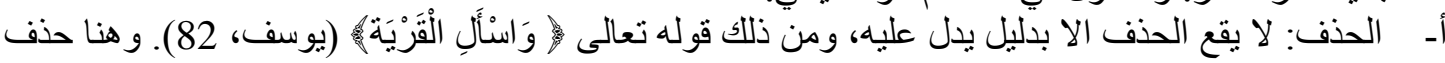
المضاف . بـ الزيادة: وهو عدول عن أصل الاقتصار. ومعنى الاقتصار أن يقوم التركيب على عناصر أقرها تأصيل

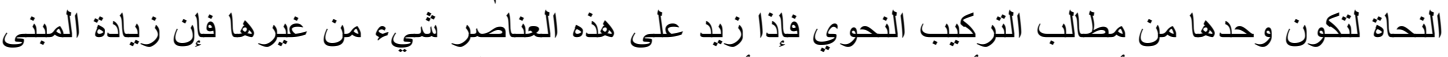

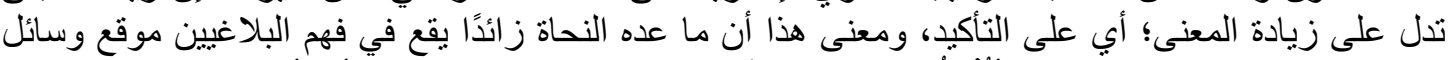

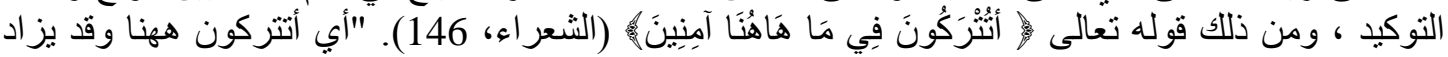

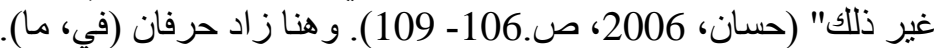

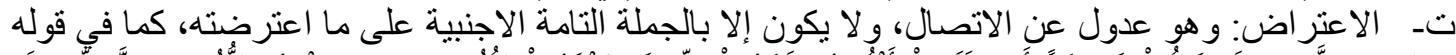

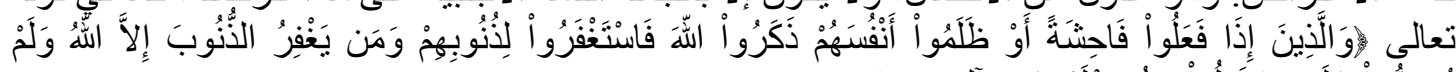

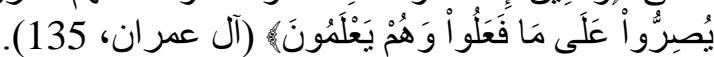

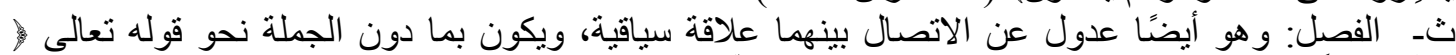

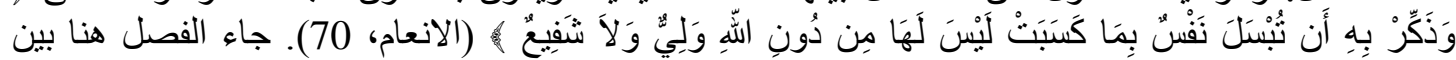

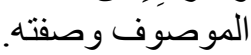

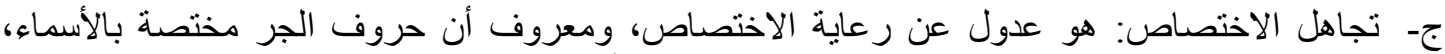

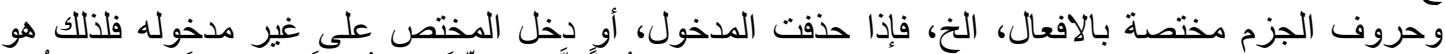

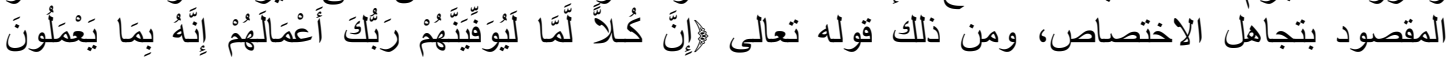

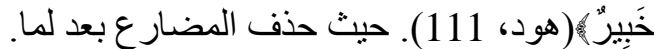

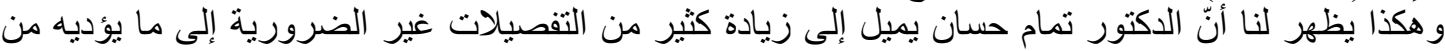

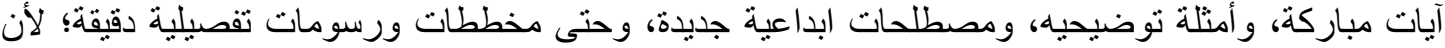
هذه التفاصيل تولد أفكارًا ابداعية جديدة. 


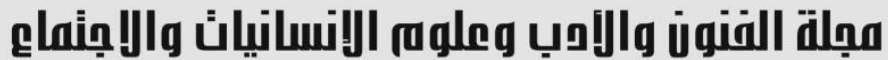

\&. Journal of Arts, Literature, Humanities and Social Sciences

www.jalhss.com

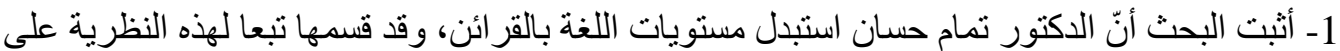

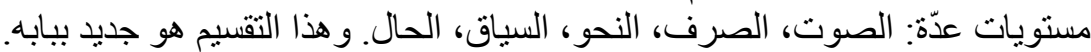

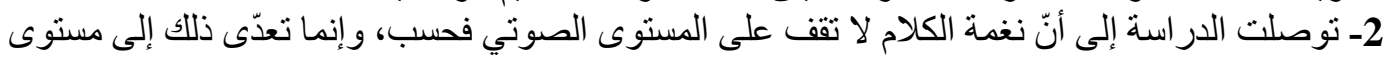

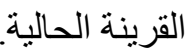
3 -أثبت البحث أن الدكتور تمام حسان انفرد في تقسيمه للقرينة النحوية، إذ قسمها على ثلاثة أقسام لم يسبقه أحد

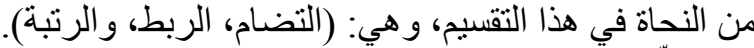

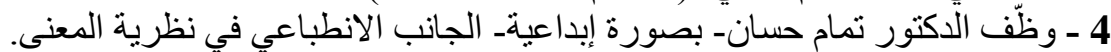

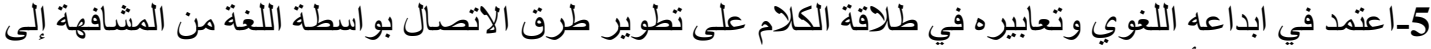

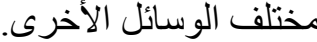

6-ارنكز الدكتور تمام حسان في نظامه اللغوي على النظام الوظيفي، و النظام المعجمي من مفردات تتوز عها

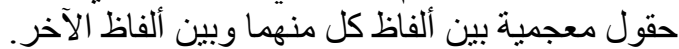

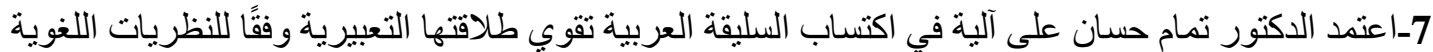

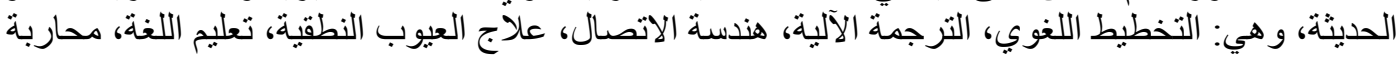

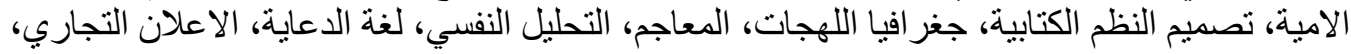

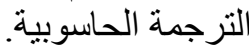
8-بيّنت الدر اسة أن موضع المرونة الذي يتمتع بها الدكتور تمام حسان في القدرة على تغيير حالته الذهنية عن

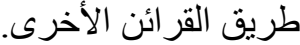

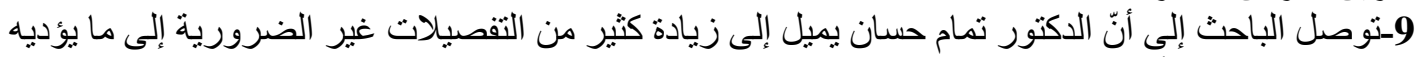

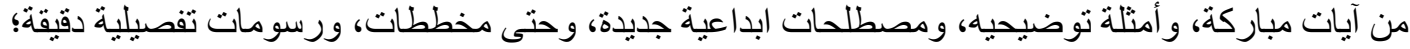
لأن هذه التفاصيل تولد أفكارًا ابداعية جديدة.

1-ابن الحاجب، جمال الدين بن عثمان بن عمر بن أبي بكر. (2010م). الكافية في النحو. ( ط.1). القاهرة: مكتبة

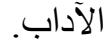
2-ابن جني، أبو القتح عثمان. (2010). التنبيه على شرح مشكل أبيات الحماسة. القاهرة: مكتبة دار الكتب

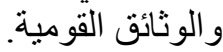

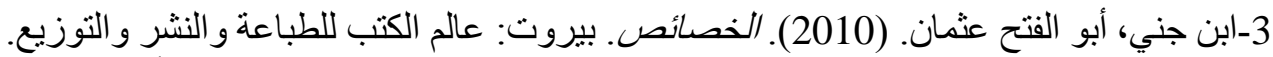

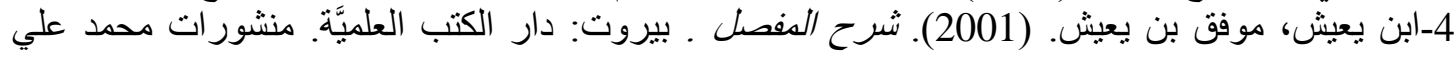
5- الأصبنهاني، أبو القاسم إسماعيل بن محمد بن الفضل القرشي. ( 1995). إعراب القرآن، الرياض: مكتبة

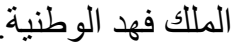
6- أنيس، إبر اهيم. ( 2003). من أسرار اللغنة. (ط.8). القاهرة: مكتبة الأنجلو المصرية.

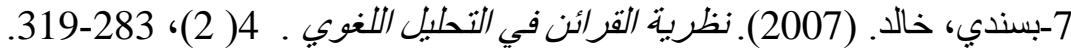
8_الجندي، أحمد علم الدين.(2002). من قضنابا الفكر الأصولي وأثثره في تبسير النحو العربي. (ط.1.). القاهرة:

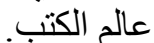

9-حسان، تمام. (2011). الفكر اللغوي الجديد. (ط.1974)، القاهرة: عالم الكتب.

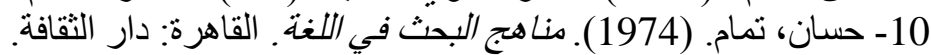

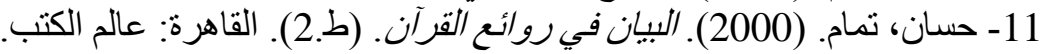

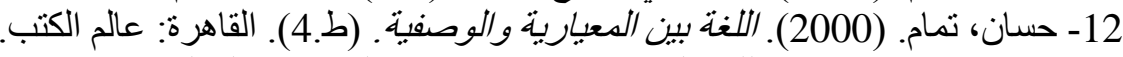

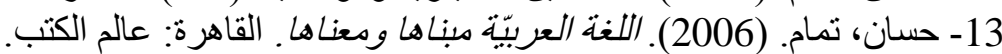

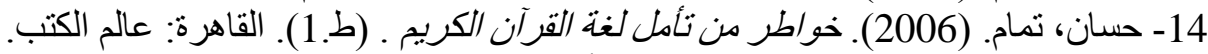
15- حسان، تمام. (2006). مقالات في اللغة والأدب .( ط.1). القاهرة: عالم المان الكتب. 


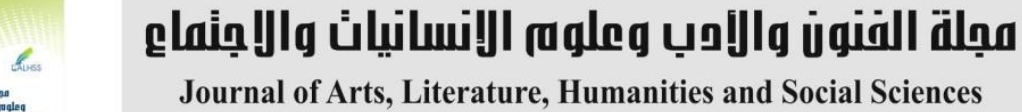

\section{www.jalhss.com}

16- حسان، تمام. (2009). الخلاصة النحوية. .(ط.3). القاهرة: عالم الكتب.

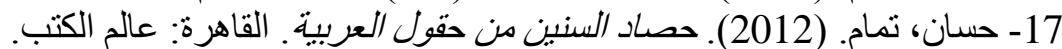

18- حسان، تمام.( 2000)، الأصول دراسة أبستمولوجية للفكر اللغوية عند العرب. القاهرة: أميرة للطباعة عالم الكتب.

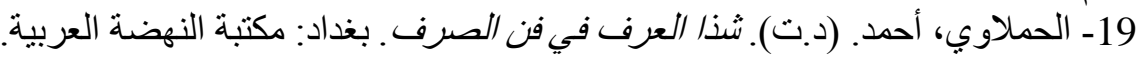
20- حميدة، مصطفى. (1997م). نظام الارتباط والربط في في تركبي الجملة العربية. (ط.1.). القاهرة: الشركة المصرية العالمية للنشر - لونجمان.

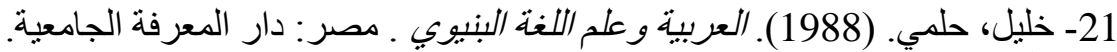

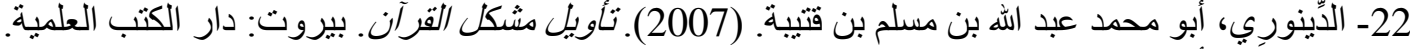

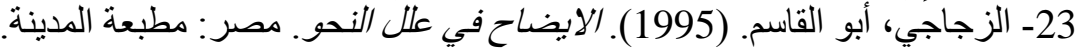

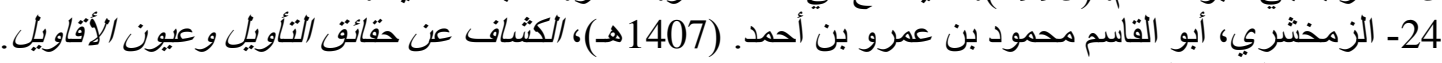
بيروت: دار الكتاب العربي. 25- الزوزني، أبو عبد الله الحسين. (د-ت). شرح دعلقة امرئ القبي. تحقيق المستشرق الألمانيّ إرنست فلهلم.

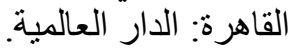
26 - زيتون، عايش محمود. (1987). تندية الابداع و التفكير الابداعي في تدربس العلوم. عمان: جمعية المطابع

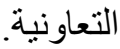
27- الساقي، فاضل مصطفى. (2008). أقسام الكلام العربي من حيث الشكل والوظبفة. تقديم د. تمام حسان. (28) - 2 القاهرة: مكتبة الخانجي. 28- السامر ائي، فاضل صالح. (2009). الجملة العربية و المعنى ـ (ط.2) عمّانـ المملكة الأردنية الهاشميّة: دار

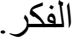
29- السبيل، عبد العزيز. (13-2- 2012). اللغة والابداع. العدد رقم (71). صفحة(19). نشرت هذه المادة في

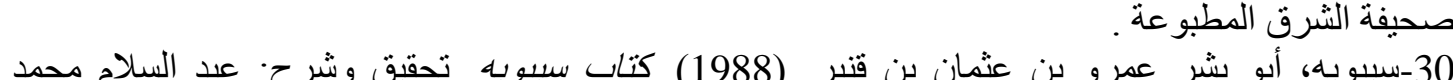

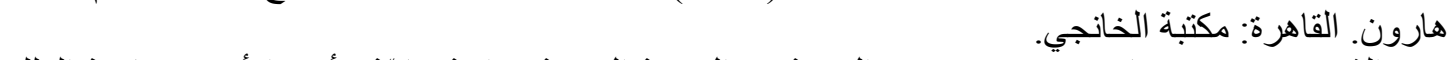
31- الثريف، تبسير عباس محمد. (2011). القربينة في البلاغة العربية دراسة بيانيّة. أربد الأردن. جامعة الملك عبد العزيز: عالم الكتب الحديث للنشر و التوزيع.

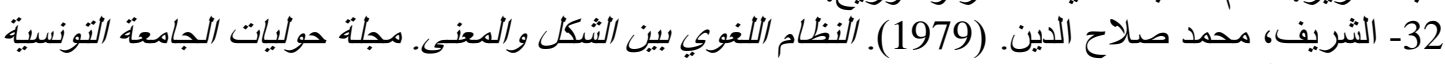

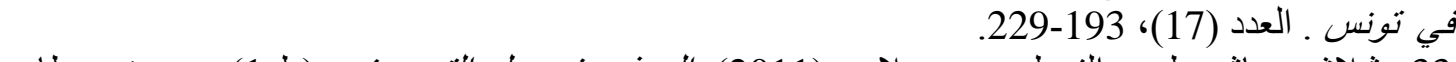

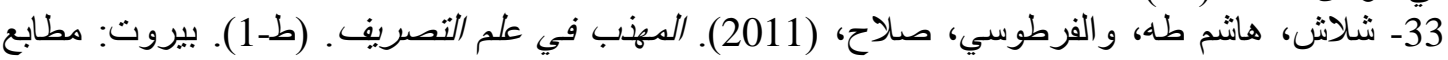

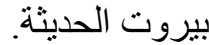
34-الصالح، صبحي. (1992). دراسات في فقه اللغة. (ط.2). بيروت: الككتبة الاهلية.

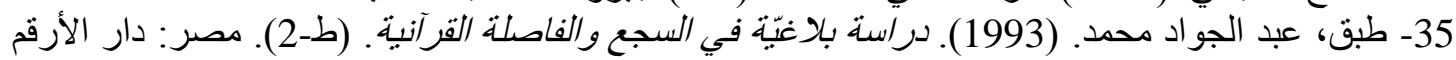

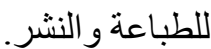

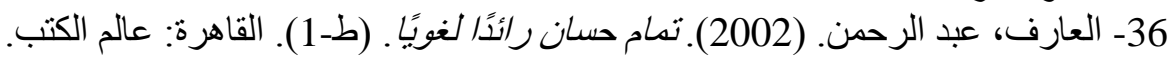

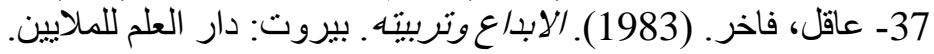

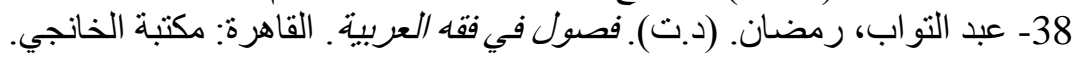

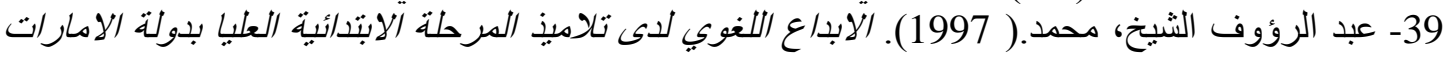

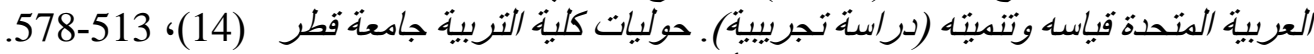

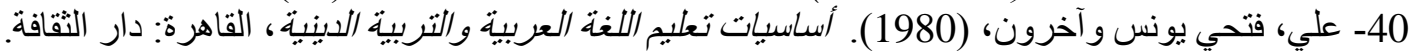

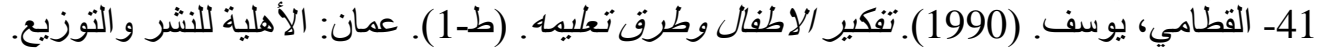

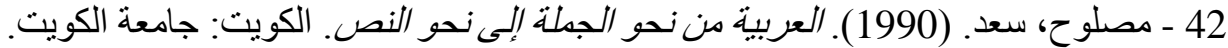

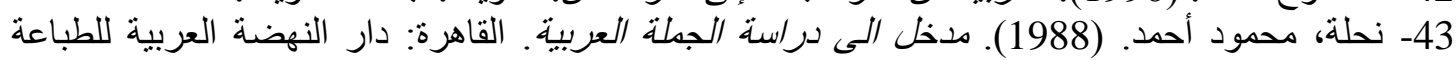

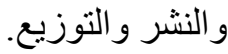




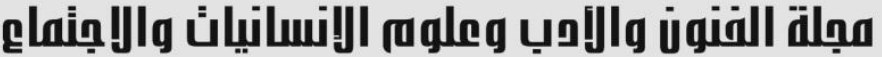

Journal of Arts, Literature, Humanities and Social Sciences

www.jalhss.com

Volume (50) March 2020

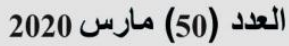

\section{References}

1 - Ibn al-Hajib, Jamal al-Din bin Othman bin Omar bin Abi Bakr. (2010). Adequate grammar. (1st ed). Cairo: Library of Arts.

2 - Ibn Jani, Abu Al-Fath Othman. (2010). Alert to explain the problem of the words of enthusiasm. Cairo: National Library and Library of Books.

3- Ibn Jani, Abu Al-Fath Othman. (2010). Properties Beirut: Book World for Printing, Publishing and Distribution.

4- Ibn Yaish, Muwaffaq bin Yaish. (2001 AD). Detailed explanation. Presented to him and put his margins and indexes Beirut: Scientific Books House. Publications of Muhammad Ali Beydoun.

5- Al-Asbhani, Abu al-Qasim Ismail bin Muhammad bin al-Fadl al-Qurashi. (1995). The syntax of the Qur'an, indexing and investigation: Dr. Faiza Bint Omar AlMoayad. Riyadh: King Fahd National Library.

6-Anis, Ibrahim. (2003 AD). Of the secrets of the language. (8th Edition). Cairo: The Anglo-Egyptian Library.

7- By Sindhi, Khalid. (2007 AD). Evidence theory in linguistic analysis. 4 (2), 283319.

8- Hassan, Tammam. (2011 AD). New linguistic thought. (1st ed), Cairo: The World of Books.

9- Hassan Tammam. (1974 AD). Research methods in language. Cairo: House of Culture.

10- Hassan, Tammam. (2000 AD). The statement in the masterpieces of the Qur'an, (2nd ed). Cairo: The World of Books.

11- Hassan, Tammam. (2000 AD). Language between normative and descriptive. (4th ed). Cairo: Books World

12- Hassan, Tammam. (2006 AD). The Arabic language has its meaning and meaning. Cairo: The World of Books.

13- Hassan Tammam. (2006 AD). Thoughts of contemplating the language of the Noble Qur'an. (1st ed). Cairo: The World of Books.

14- Hassan, Tammam. (2006 AD). Articles on language and literature (1st ed). Cairo: The World of Books.

15- Hassan Tammam. (2009). Grammatical Compendium (3rd ed). Cairo: The World of Books.

16- Hassan Tammam. (2012). Harvest the years from the fields of Arabia. Cairo: The World of Books.

17- Hassan, Tammam (2000), Al-Asul, an epistemological study of linguistic thought among Arabs. Cairo: Amira Printing World of Books.

18- El Hamalawy, Ahmed. D.T. Shaza custom in the art of exchange. Baghdad: The Arab Renaissance Library.

19- Hamida, Mostafa. (1997 AD). Link system in the syntax of the Arab sentence. (st

ed) 1. Cairo: Egyptian International Publishing Company - Longman.

20- Khalil, my dream. (1988 AD). Arabic and structural linguistics. Egypt:

University Knowledge House. 


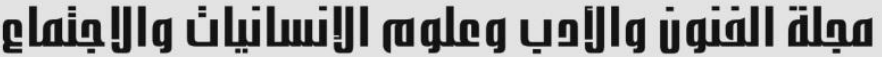

Journal of Arts, Literature, Humanities and Social Sciences www.jalhss.com

21- Al-Dinururi, Abu Muhammad Abd Allah Ibn Muslim Ibn Qutaiba. (2007 AD). Interpretation of the problem of the Qur'an, Ibrahim Shams al-Din's comment. Beirut: Scientific Books House.

22- Al-zaggage Abu al-Qasim. (1995 AD). Clarification as to the ills. Achievement: Mazen Al-Mubarak. Egypt: City Press.

23- Al-Zamakhshari, Abu al-Qasim Mahmoud bin Amr bin Ahmed. (1407 AH). The detector. Beirut: The Arab Book House.

24- Al-Zuzani, Abu Abdullah al-Hussein. D-T. Explanation hanging suspended person Qais. For weighty. The investigation of German orientalist Ernst Wilhelm. Cairo: International House.

25- Olive, Ayesh Mahmoud. 1987 AD. Development of creativity and creative thinking in science education. Amman: Cooperative Press Association.

26-Al-Saqi, Fadel Mustafa. (2008 CE). Sections of Arabic speech in terms of form and function. Presentation of Dr. Tamam Hassan. (2nd Ed) Cairo: Al-Khanji Library.

27- The Samurai, Fadel Saleh. (2009). Arabic sentence and meaning. (2nd Ed) Amman - The Hashemite Kingdom of Jordan: Dar Al-Fikr

28- Al-Sabeel, Abdul Aziz. (13-13-2012). Language and creativity. No. 71. Page (19). This article was published in Al Sharq Newspaper.

29-Sibawayh, Abu Bishr Amr ibn Othman bin Qanbar. (1988 AD). Sibawayh Book. Investigation and explanation: Abd al-Salam Muhammad Harun. Cairo: Al-Khanji Library.

30- Sharif, Tayseer Abbas Muhammad. (2011 AD). Context in Arabic rhetoric is a graphic study. Jordan. King Abdulaziz University: Modern World of Books for Publishing and Distribution.

31- Shalash, Hashem Taha, and Al-Fartousi, Salah, (2011). Polite in conjugation. (1st ed). Beirut: Beirut Modern Printing Press.

32-Al-Saleh, Subhi. (1992 AD). Studies in philology. (2nd Ed). Beirut: The National Library.

33- Dish, Abdel-Gawad Mohamed. (1993 AD). A rhetorical study of Al-Sajaa and the Qur'anic comma. (1st ed). Egypt: Dar Al-Arqam for Printing and Publishing.

34-Al-Aref, Abdel Rahman. (2002 AD). Tamam Hassan is a linguist. (1st ed). Cairo: The World of Books.

35- Sane, luxurious. (1983 AD). Creativity and its upbringing. Beirut: Dar al-Alam for millions.

36- Abdel Tawab, Ramadan. D.T. Chapters in Arabic jurisprudence. Cairo: AlKhanji Library.

37- Abdul Raouf Al-Sheikh, Muhammad (1997 AD). Linguistic creativity for upper primary school students in the United Arab Emirates, its measurement and development (experimental study). Annals of the College of Education, Qatar University (14), 531-578.

38- Ali, Fathi Younis and others, (1980 AD). Fundamentals of Teaching Arabic Language and Religious Education, Cairo: House of Culture. 


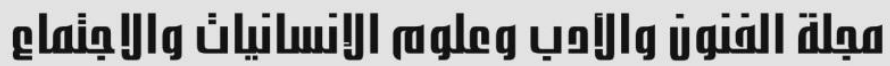

Journal of Arts, Literature, Humanities and Social Sciences www.jalhss.com

39- Al-Qatami, Youssef. (1990 AD). Children's thinking and teaching methods. (1st ed). Amman: Al Ahlia Publishing and Distribution.

40- Reformer, Saad. (1990 AD). Arabic from about sentence to about text. Kuwait University.

41- The soldier, Ahmed Alam al-Din. (2002). One of the issues of fundamentalist thought and its impact on facilitating Arabic grammar. (1st ed). Cairo: The World of Books.

42 - Nahli, Mahmoud Ahmed. (1988 AD). Introduction to the study of the Arabic sentence. Cairo: Arab Renaissance House for Printing, Publishing and Distribution. 43-Sharif, Mohamed Salah El-Din. (1979 AD). The linguistic system between form and meaning. Annals of the Tunisian University Annals. Number (17), 193-229. 